\title{
Experimental Validation of a Semi-dynamic Simplified Model of Active Pipe-embedded Building Envelope
}

\author{
Qiuyuan $\mathrm{Zhu}^{\mathrm{a}}$, Anbang $\mathrm{Li}^{\mathrm{b}}$, Junlong Xie ${ }^{\mathrm{c}, *}$, Weiguang $\mathrm{Li}^{\mathrm{d}}$, Xinhua $\mathrm{Xu}^{\mathrm{b}}$
}

\begin{abstract}
Active pipe-embedded building envelope can allow for substantial heat flow for relatively small temperature difference due to the embedded pipes in the external wall/roof. This structure can directly utilize the low-grade sources for reducing building cooling/heating load and improving indoor thermal comfort by intercepting the heat gain/loss through the building envelope due to the circular water inside the embedded pipe. This paper presents the experimental validation of a semi-dynamic simplified model of the active pipe embedded building envelope. The experiment test rig consists of two environment chambers with one for simulating the ambient environment and one for indoor environment with a pipe-embedded building envelope sample separating both chambers. A small chiller and a buffer tank are installed to provide stable water temperature for the test sample. The temperatures and heat fluxes on both sides of the test sample, the inlet and outlet water temperature as well as flow rate are measured. The measured boundary conditions are used as the inputs of the semi-dynamic simplified model for calculating the thermal performance of the active structure. The results show the semi-dynamic simplified model can predict the semi-steady or pure dynamic thermal performance of the pipe-embedded building envelope very well by comparing with the measurement.
\end{abstract}

Keyword: Active pipe-embedded building envelope, semi-dynamic simplified model, Experimental validation 


\section{Introduction}

Active pipe-embedded building envelope is proposed recently [1, 2]. This structure is a building envelope with pipe embedded in the external wall/roof and can utilize circulating water in the pipe to remove/release heat inside the structure directly. Active pipe-embedded building envelope is similar with pipe-embedded floors or ceilings for radiant heating/cooling. Pipe-embedded floors or ceilings allow substantial heat flows even for relatively small temperature difference between the mass and water and can utilize low-grade energy sources since the heat transfer surface between the slab mass and water is very large [3-5]. Active pipe-embedded building envelope also has this advantage. In addition, another advantage of this structure is that it can intercept the heat/cold permeation through the external wall from outdoor environment to indoor space. As a result, the indoor cooling load or heating load is reduced by directly using the low-grade energy without involving any mechanical cooling/heating equipment. Of floors or ceilings for radiant heating/cooling when the wall is highly insulated from outdoor environment. Usually, groundwater, the cooling water produced by cooling towers, and geothermal energy produced by the ground-coupled heat exchanger system etc. can be used as the low-grade energy sources [6-8]. These low-grade energy sources are almost free and energy is only consumed by the circulating water pump.

The heat transfer model of the building envelope are essentially needed for estimating the cooling or heating energy consumption for performance monitoring, diagnosis and control strategy analysis [9-14]. Active pipe-embedded building envelope is different from the traditional building envelope due to the pipe-embedded layer. The material of the pipe embedded layer may be concrete or plaster. Due to the pipe-embedded layer and embedded pipes, the heat transfer of the active pipe-embedded building envelopes becomes complicated, and the model for heat flow calculation is not easy to develop. The heat transfer model of active pipe-embedded building envelope is rarely mentioned although the models of pipe-embedded structures (such as 
pipe-embedded structure for snow melting system, pipe-embedded floors, and pipe-embedded ceiling) are presented by many researchers [15-21].

As far as simplified model for pipe-embedded floor/ceiling is concerned, Koschenz and Dorer [21] developed a simplified steady-state pure resistant model of the pipe-embedded ceiling for air-conditioning. Weber and Jóhannesson [22] presented a dynamic simplified RC-network model for the pipe-embedded floor/ceiling, and this model is validated by measurement in time domain [23]. Dynamic simplified model are preferable to predict the dynamic thermal process in the structure for thermal performance prediction, and can be integrated with conventional energy simulation software such as TRNSYS, EnergyPlus, and DeST etc. [24, 25].

Active pipe-embedded building envelope is similar to the pipe-embedded floors/ceiling in terms of structure. For the heat transfer of the pipe-embedded floor/ceiling, it is only affected by the indoor environment disturbance and the circular water disturbance in the embedded pipe. The heat transfer problem can be easily simplified because the indoor environment disturbance does not change abruptly and even may be regarded as constant if the solar radiation is absent [26, 27]. However, the heat transfer of the active pipe-embedded building envelope is affected additionally and significantly by the outdoor environment especially when the outside of the building envelope is not enclosed with a thick insulation-skin. The brick or concrete exterior wall without insulation outside is still widely used in rural regions and many urban buildings in China. The outdoor thermal disturbances such as solar radiation and air temperature etc. change much more abruptly than the indoor environment disturbance. In this case, the fore-mentioned heat transfer models of pipe-embedded floor/ceiling may not be effectively used for the pipe-embedded building envelope. Therefore, it's necessary to develop a more efficient and accurate heat transfer model of the pipe-embedded building envelope which may be subjected to abrupt thermal disturbances.

For the heat transfer analysis of the pipe-embedded building envelope, Zhu et al. [2] presented a two-dimensional numerical frequency-domain finite difference (FDFD) model for analyzing the frequency thermal response of this structure under various disturbances. The heat transfer along the pipe line was not considered in the FDFD model due to the assumption that the water temperature change along the pipe line is very small. 
91 This FDFD model was further validated by experimental measurements in time domain by Xie et al. [28]. Zhu et al. [29, 30] developed a dynamic simplified thermal model (RC model) of this structure for evaluating the frequency thermal characteristic along the width direction (i.e., the heat transfer along the pipe length direction is neglected), and the model parameters are identified by using Genetic Algorithm to match its frequency thermal response with the theoretical thermal response predicted by the FDFD model. Furthermore, Zhu et al. [31] presented a semi-dynamic simplified model (i.e. the coupled RC model and NTU model) of this structure by considering the heat transfer (i.e. RC model) along the width direction of the wall and the heat transfer (i.e. NTU model) along the direction of the pipeline. This model is more preferable for practical engineering application since it can predict the heat transfer along the width direction of the wall (such as the surface temperature or heat flux) and the outlet water temperature and total heat transfer between the wall and circulating water. This model is numerically validated by CFD model [31].

Although highly insulation layer for building envelope for very low $R$ value is not involved in the Ref [31], the simplified heat transfer model of the pipe-embedded exterior wall developed in the Ref [31] is still applicable to exterior walls with external skin of low R-value such as with insulation layer. This wall can be modeled simply and directly by adding a resistant component (i.e., R) to the exterior node of the developed simplified RC-network model presented in the Ref [31].

This study mainly reports the setup of experiment test rig and the experimental validation of the semi-dynamic simplified model of the active pipe-embedded building envelope. The measured boundary conditions are used as the inputs of the semi-dynamic simplified model for thermal performance prediction. The outlet water temperature and the surface heat flux etc. are used for comparison to validate the semi-dynamic simplified model including the prediction of semi-dynamic thermal performance and dynamic thermal performance. The paper is organized as follows. At the beginning, the semi-dynamic simplified model of the active pipe-embedded building envelope is roughly briefed. Then, the experimental setup is described. Finally, the semi-steady state of this experiment is analyzed and the experimental validation is presented.

\section{Description of the semi-dynamic simplified model}

Figure 1(a) shows the structure of the pipe-embedded building envelope. This 
structure consists of a $15 \mathrm{~mm}$ internal mortar layer, a $120 \mathrm{~mm}$ brick layer, a pipe-embedded mortar layer, a $120 \mathrm{~mm}$ brick layer, and a $15 \mathrm{~mm}$ external mortar layer in sequence. Polybutylene tubes with the diameter of $20 \mathrm{~mm}$ is used since polybutylene is economic, durable, and allow heat to pass through efficiently. The unit section abcd (which is the typical cross section of this structure) is used for model development. The heat transfer resistance due to the pipe width is very small when compared with the resistance of the brick layer or mortar layer. Therefore the thickness of pipe is neglected for investigating the thermal performance of the active pipe-embedded building envelope conveniently. Usually, the pipe-embedded building envelope may have different pipe spacings such as $100 \mathrm{~mm}, 150 \mathrm{~mm}, 200 \mathrm{~mm}, 250 \mathrm{~mm}$ and $300 \mathrm{~mm}$ etc. in practical applications. In this study, the pipe spacing is taken as $200 \mathrm{~mm}$.

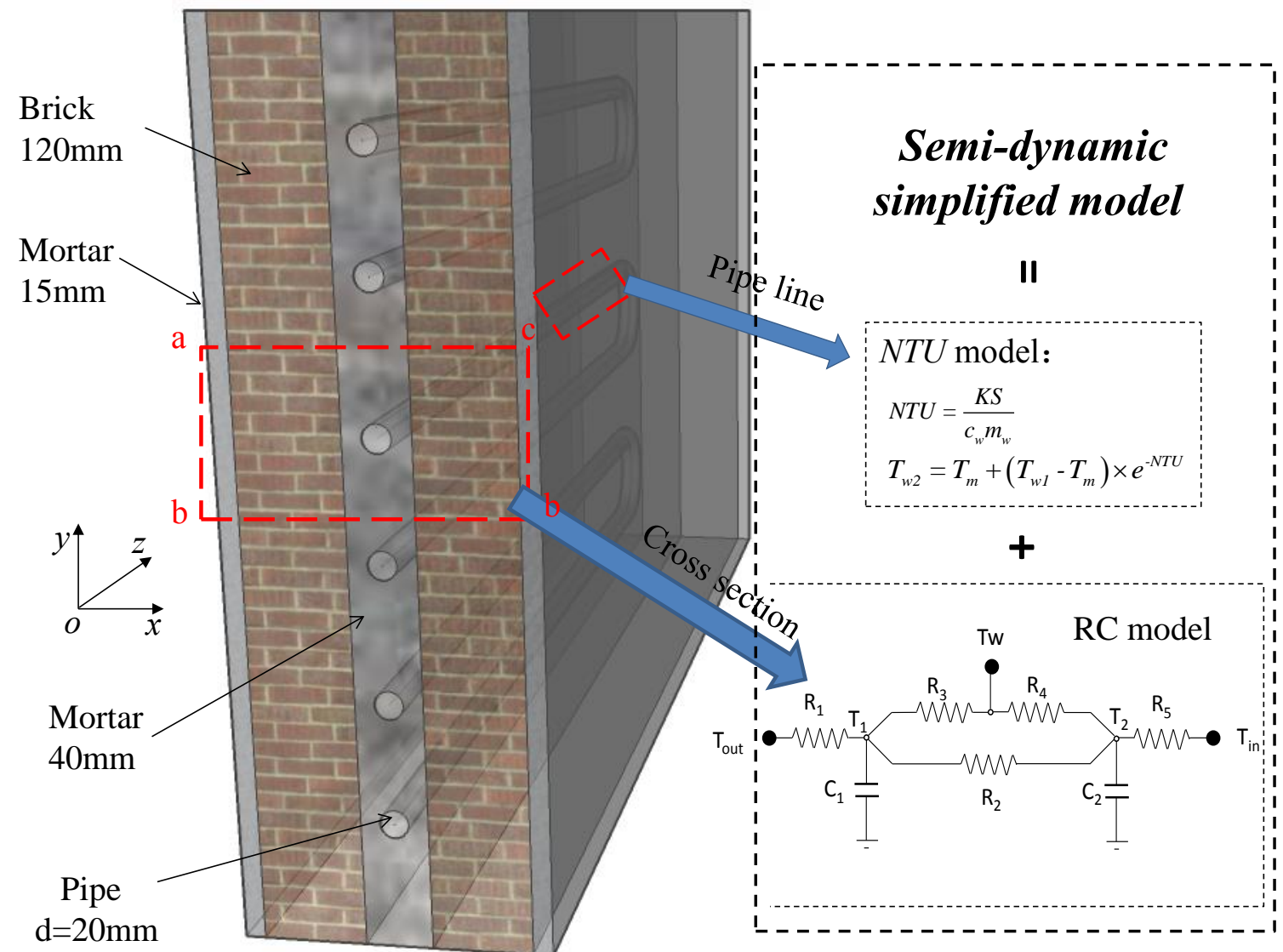

(a)

(b)

Figure 1 Schematic of the active pipe-embedded building envelope and model simplification.

(a) the structure, (b) semi-dynamic simplified model

The semi-dynamic simplified model is a coupled model which is composed of a RC model (i.e., 5R2C model) and a NTU model, as shown in Figure 1. The RC model is a 
simplified thermal-network model for predicting the dynamic heat transfer within the cross section abcd (see Figure 1(a)), i.e., the heat transfer within xoy plane, based on the simplification that the heat transfer along the pipe length direction is neglected. NTU or $N T U-\varepsilon$ model (i.e., effectiveness-number of transfer units) is a well-known method for solving heat transfer problems for sensible heat exchanger [32]. The $N T U$ model can offset the disadvantage of the RC model, and it is used to predict the heat transfer along the pipe length direction, i.e., the $z$ direction as shown in Figure 1(a).

As shown in Figure 1(b), the RC model is a dynamic second-order simplified thermal-network model. Only two capacity nodes (i.e., $C_{1}$ and $C_{2}$ ) are used to represent the capacity of the whole pipe-embedded structure, which will decrease the computation time to a large degree. $R_{1}, R_{2}, R_{3}, R_{4}$ and $R_{5}$ are the thermal resistance components between two adjacent temperature nodes. In this model, $T_{\text {out }}$ is the outdoor air temperature, $T_{i n}$ is the indoor air temperature, and $T_{w}$ is the average temperature of the water. $T_{1}$ and $T_{2}$ are the inside node temperatures of the RC model. The parameters of the RC model are determined by using a GA-based parameter identification by matching its frequency thermal responses with the theoretical frequency thermal responses predicted by the Frequency Domain Finite Difference (FDFD) model. The detailed description about the identification procedure can be found in Ref. [30]. NTU model is shown in Figure 1(b). $K$ is the overall heat transfer coefficient, $L$ is the total length of the pipe, $N T U$ is the number of transfer units, $S$ is the area of the pipe, $D$ is the diameter of the pipe, $T_{w 1}$ and $T_{w 2}$ are the inlet and outlet water temperatures respectively. $T_{m}$ is the average temperature of the structure mass. It represents the average temperature over the width of the structure at a time. It is a virtual temperature and an intermediate variable used in $N T U$ model. It can be calculated by taking the arithmetic mean value of the $T_{1}, T_{2}, T_{w}, T_{\text {out }}$ and $T_{i n}$.

The RC model and NTU model are coupled together (called semi-dynamic model) by the link of $T_{m}, T_{1}$, and $T_{2}$ etc. The detailed model descriptions and solving process of the semi-dynamic model can be found in Ref. [31]. By using this coupled semi-dynamic model of the pipe-embedded building envelope, the average surface heat fluxes and temperatures (including exterior wall surface, pipe surface and interior wall surface) and outlet water temperature can be predicted directly and easily with the indoor and outdoor air temperatures and inlet water temperature are given as inputs. The dynamic thermal performance of this pipe-embedded structure can be further evaluated. 


\section{Experiment setup}

Actual experiments are preferable for validating the accuracy of a simulation model or a numerical solution. In this paper, an actual experiment rig of the active pipe-embedded building envelope is assembled, and it can be used to measure the heat transfer performance and validate the accuracy of the semi-dynamic simplified model of this structure.

Figure 2 shows the schematics of the experiment test rig for the active pipe-embedded building envelope. This experiment test rig for the active pipe-embedded building envelope consists of five parts: (1) two heat insulation chambers (i.e., environment chambers) with one for simulating the outdoor environment and the other for simulating the indoor environment; (2) the test sample (i.e., the active pipe-embedded building envelop test sample); (3) water system for supplying the circular cooling water through the embedded pipe; (4) environment control system by using ceramic PTC heater and regulator for heating, (5) Data acquisition system etc.

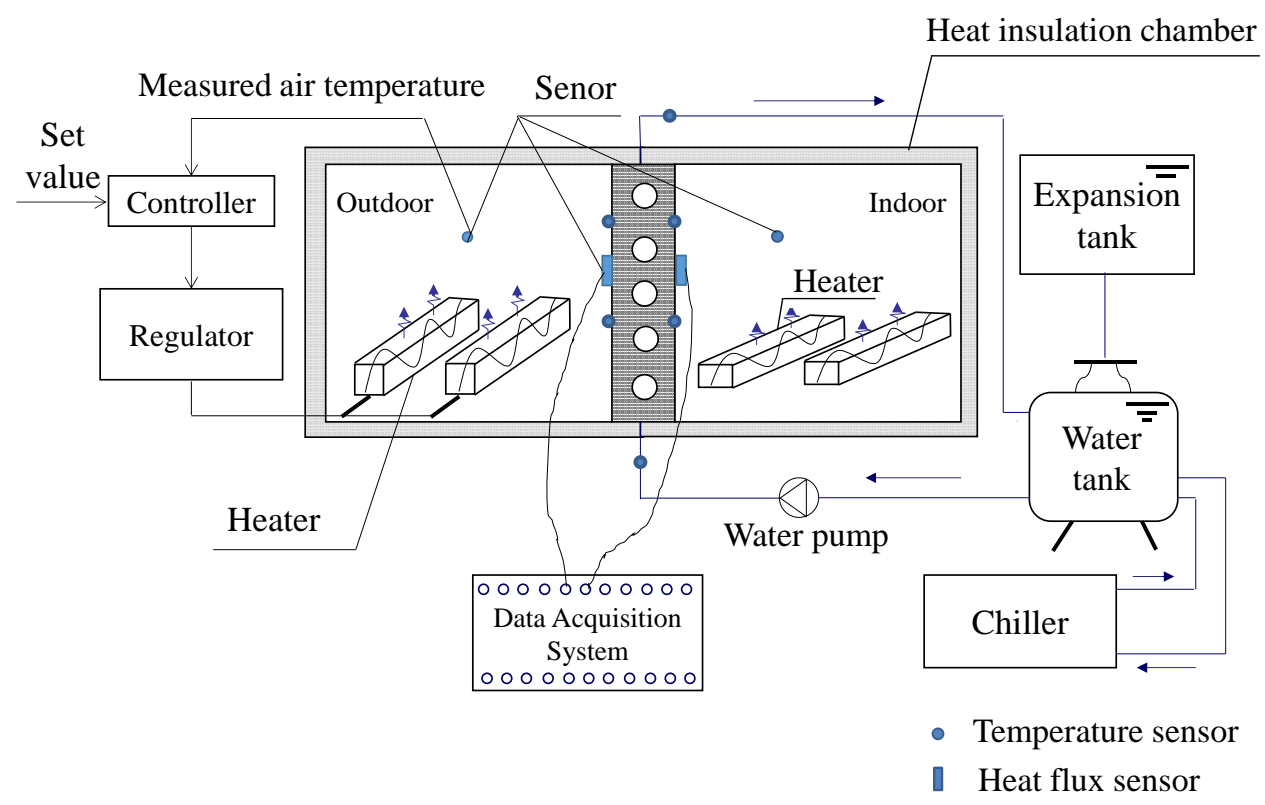

Figure 2 Schematics of the experiment test rig for the active pipe-embedded building envelope

\subsection{Heat insulation chamber}

Two heat insulation chambers were built in the room with $7260 \mathrm{~mm} \times 4700 \mathrm{~mm} \times 3000$ $\mathrm{mm}$ as shown Figure 3. One of them is used to simulate the indoor environment, and the size is $3300 \mathrm{~mm} \times 3350 \mathrm{~mm} \times 2800 \mathrm{~mm}$. The other is used to simulate the outdoor 
environment with the size of $3300 \mathrm{~mm} \times 2250 \mathrm{~mm} \times 2800 \mathrm{~mm}$.

The performance of the heat insulation chamber is very important. ASHRAE standard specifies that the resistance of the interior wall, external wall, and roof should be equal or greater than $1.5,2.0$ and $3.0 \mathrm{~m}^{2} \cdot \mathrm{K} / \mathrm{W}$ respectively [33]. In this study, $75 \mathrm{~mm}$ color steel plate (i.e., polyurethane panel with the width of $72 \mathrm{~mm}$ is covered by two thin steel plate) is used as the envelope, and then XPS extruded plate with the width of 50mm is pasted on the internal surface of the color steel plate as shown in Figure 4. The detailed properties of the wall in SI unit are given in Table 1.

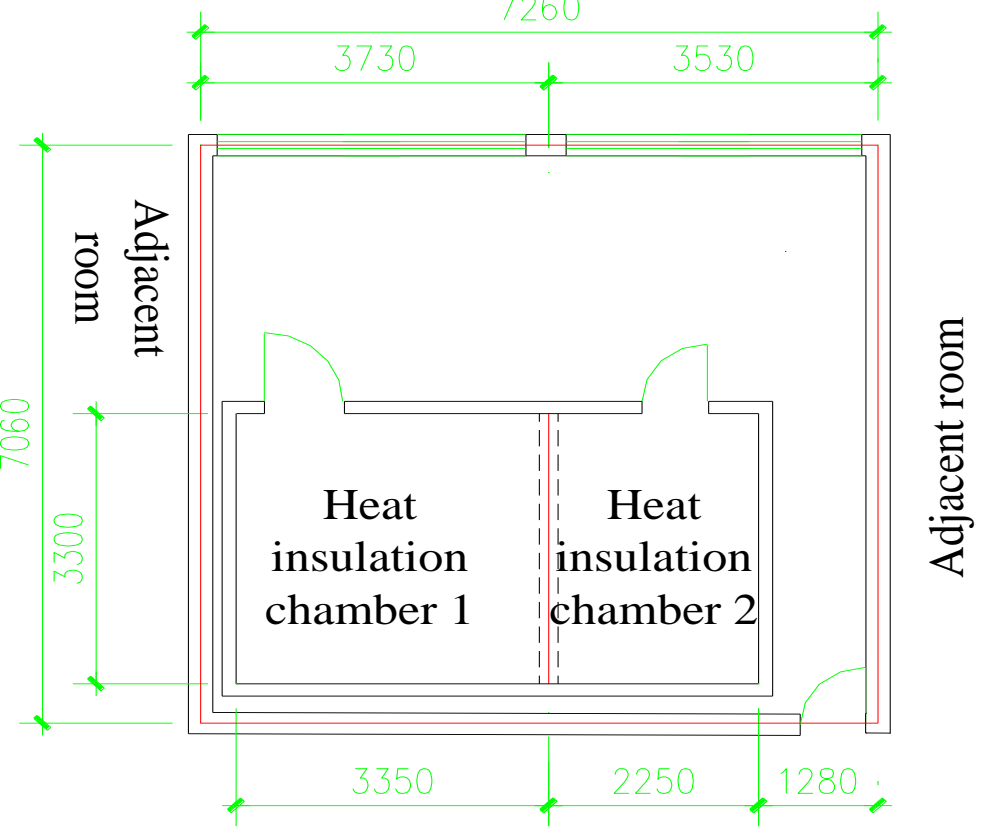

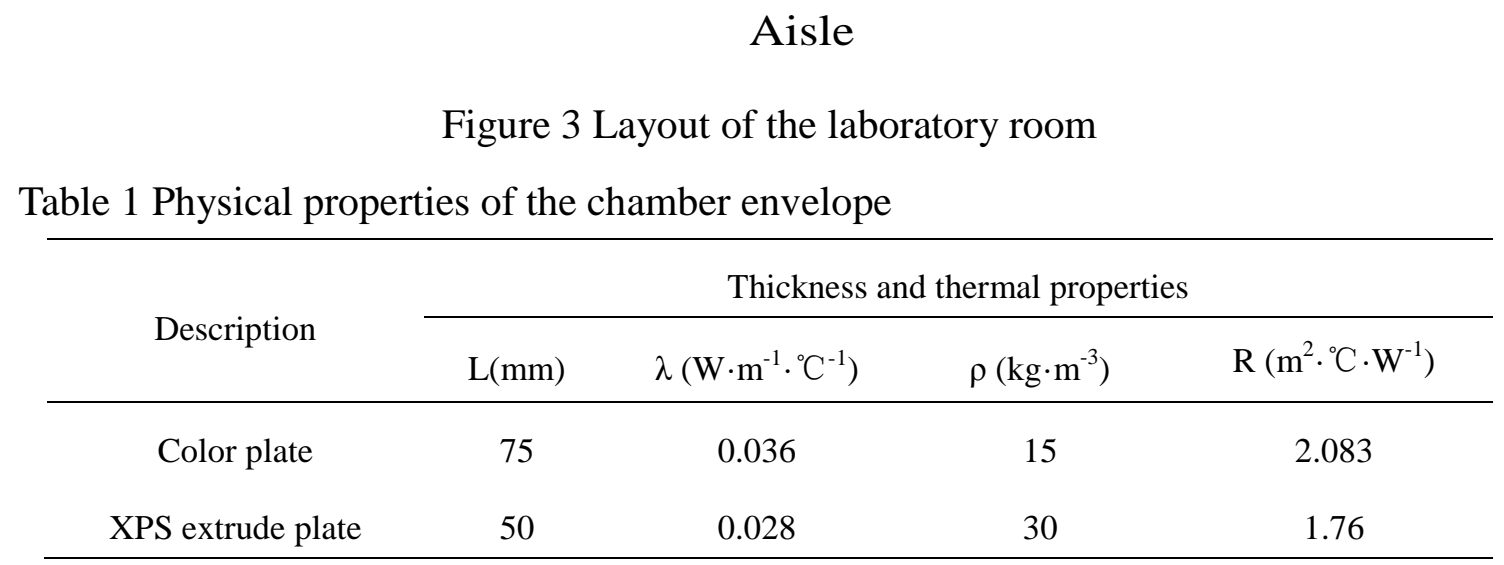




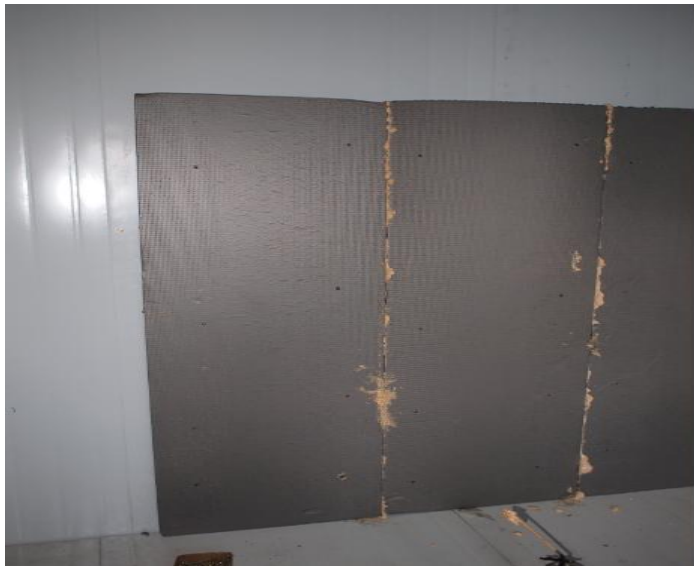

(a)

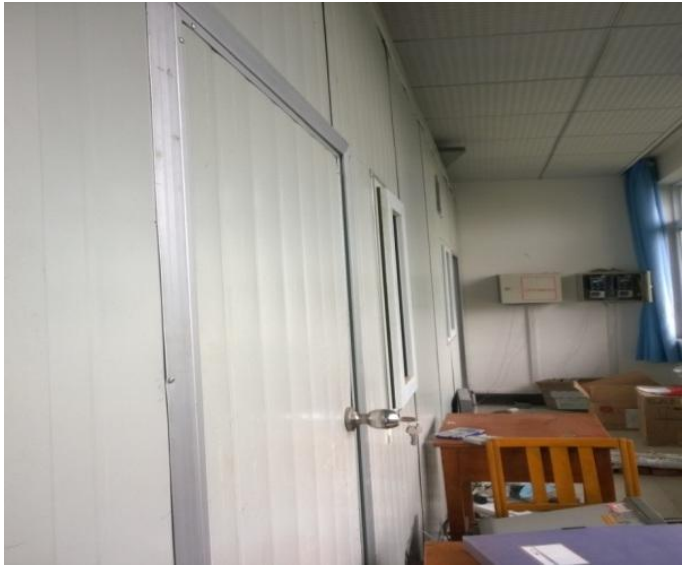

(b)

Figure 4 Appearance of the heat insulation chamber

\subsection{Construction of the test sample}

The test sample of the pipe-embedded building envelope is constructed in field in the laboratory. The length of the test sample wall is $3300 \mathrm{~mm}$, the height is $2400 \mathrm{~mm}$, and the width is $310 \mathrm{~mm}$. This sample consists of two bricks of $120 \mathrm{~mm}$ as the construction layer, and mortar layer of $40 \mathrm{~mm}$ is added in between these two bricks as embedded-pipe layer and mortar layer of $15 \mathrm{~mm}$ as the external surface and internal surface respectively. The schematic of the cross section of the active pipe-embedded building envelope is shown in Figure 1(a). The detailed properties of the materials for this sample in SI unit are given in Table 2. The density, thermal conductivity, and the specific thermal capacitance are measured in laboratory.

Table 2 Physical properties of the pipe-embedded building envelope test sample

\begin{tabular}{cccccc}
\hline \multirow{2}{*}{ Description } & \multicolumn{5}{c}{ Thickness and thermal properties } \\
\cline { 2 - 6 } & $L(\mathrm{~mm})$ & $\lambda\left(\mathrm{W} \cdot \mathrm{m}^{-1} \cdot{ }^{\circ} \mathrm{C}^{-1}\right)$ & $\rho\left(\mathrm{kg} \cdot \mathrm{m}^{-3}\right)$ & $C_{p}\left(\mathrm{~J} \cdot \mathrm{kg}^{-1} \cdot{ }^{\circ} \mathrm{C}^{-1}\right)$ & $R\left(\mathrm{~m}^{2} \cdot{ }^{\circ} \mathrm{C} \cdot \mathrm{W}^{-1}\right)$ \\
\hline \multirow{2}{*}{ Brick } & 240 & 0.76 & 1790 & 1025 & 0.316 \\
Motar & 70 & 1.71 & 2234 & 1160 & 0.041 \\
\hline
\end{tabular}

Due to the embedded pipe, the construction process of the active pipe-embedded building wall is different from that of conventional walls. The construction process of the active pipe-embedded building wall has four steps as follows. (1) A brick wall of $120 \mathrm{~mm}$ width with mortar layer of $15 \mathrm{~mm}$ is built in advance as shown in Figure 5(a). (2) The polypropylene pipe is used as the embedded pipe and parallel arranged in the inner side of the brick wall, as shown in Figure 5(b). The pipe spacing is $200 \mathrm{~mm}$. (3) The 
embedded-pipe layer and the other brick wall are built simultaneously as shown in Figure 5(c). The way to build the embedded-pipe layer is the key step. The mortar should be filled in the embedded-pipe layer simultaneously when the brick is constructed for ensuring the embedded pipe to contact with the mortar completely. (4) The mortar layer of $15 \mathrm{~mm}$ width on both external surface and internal surface are constructed for allowing the uniform heat transfer on these surfaces after the main construction is completed, as shown in Figure 5(d).

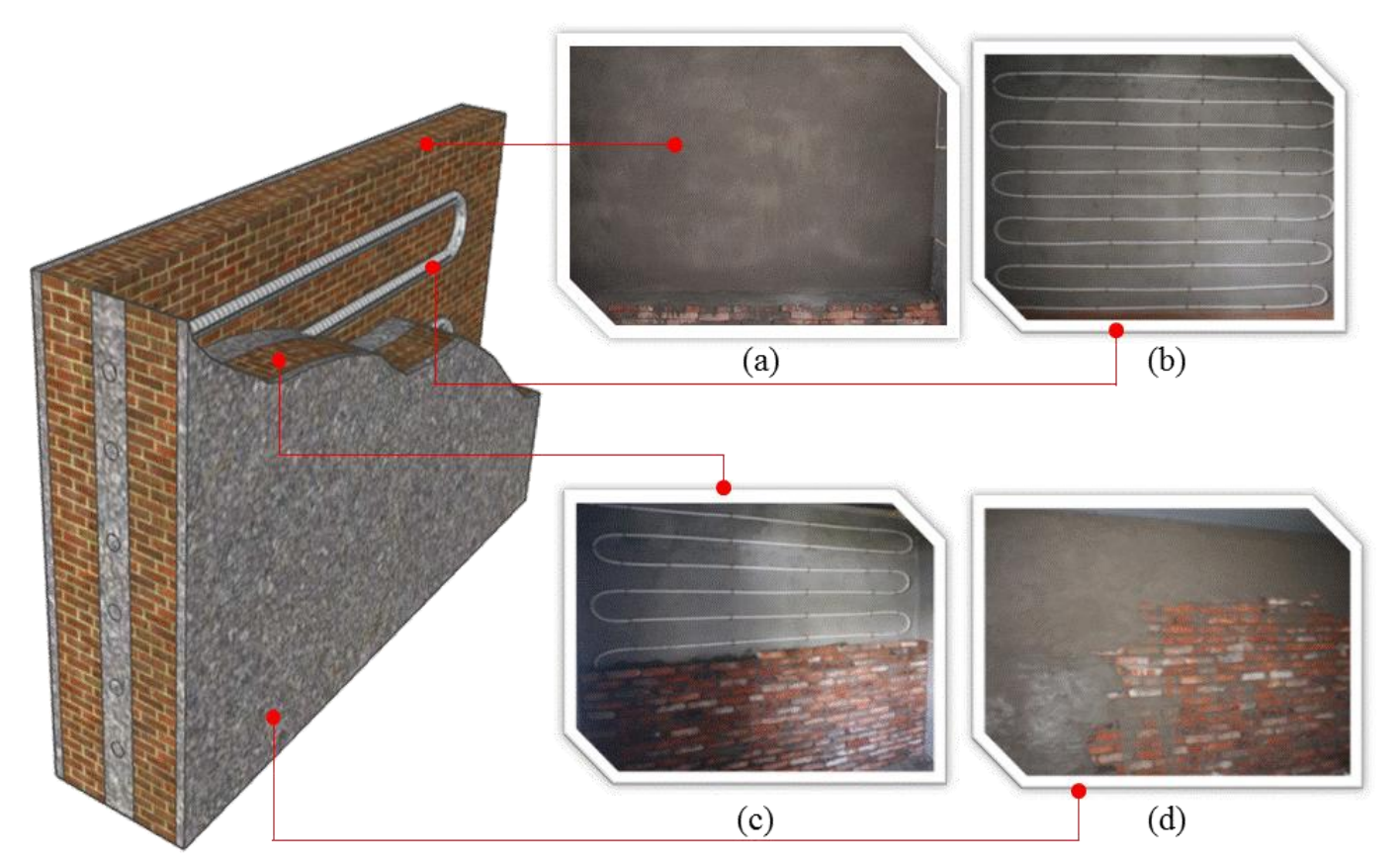

Figure 5 Construction process of the active pipe-embedded building wall [28]

\subsection{Water system design}

The fluctuation of the supply water temperature of the active pipe embedded building envelope system will significantly affect the heat transfer of the active pipe-embedded building envelops since it is a low temperature difference heat transfer. In the water system, the supply water temperature should be controlled to be constant as required during the experiment. The cool water is produced by a small chiller which simulates a ground-coupled heat exchanger or a ground aquifer etc. This chiller can control the supply water temperature within the range of $\pm 0.5{ }^{\circ} \mathrm{C}$. It cannot satisfy the experiment requirement. Therefore, a buffer tank is designed in the water loop. Figure 6 shows the water system in which a buffer tank is added at the supply water pipe. The fluctuation of the supply cooling water temperature to the active pipe embedded building envelope sample can be eliminated by the lager amount cooling water in the buffer tank. 


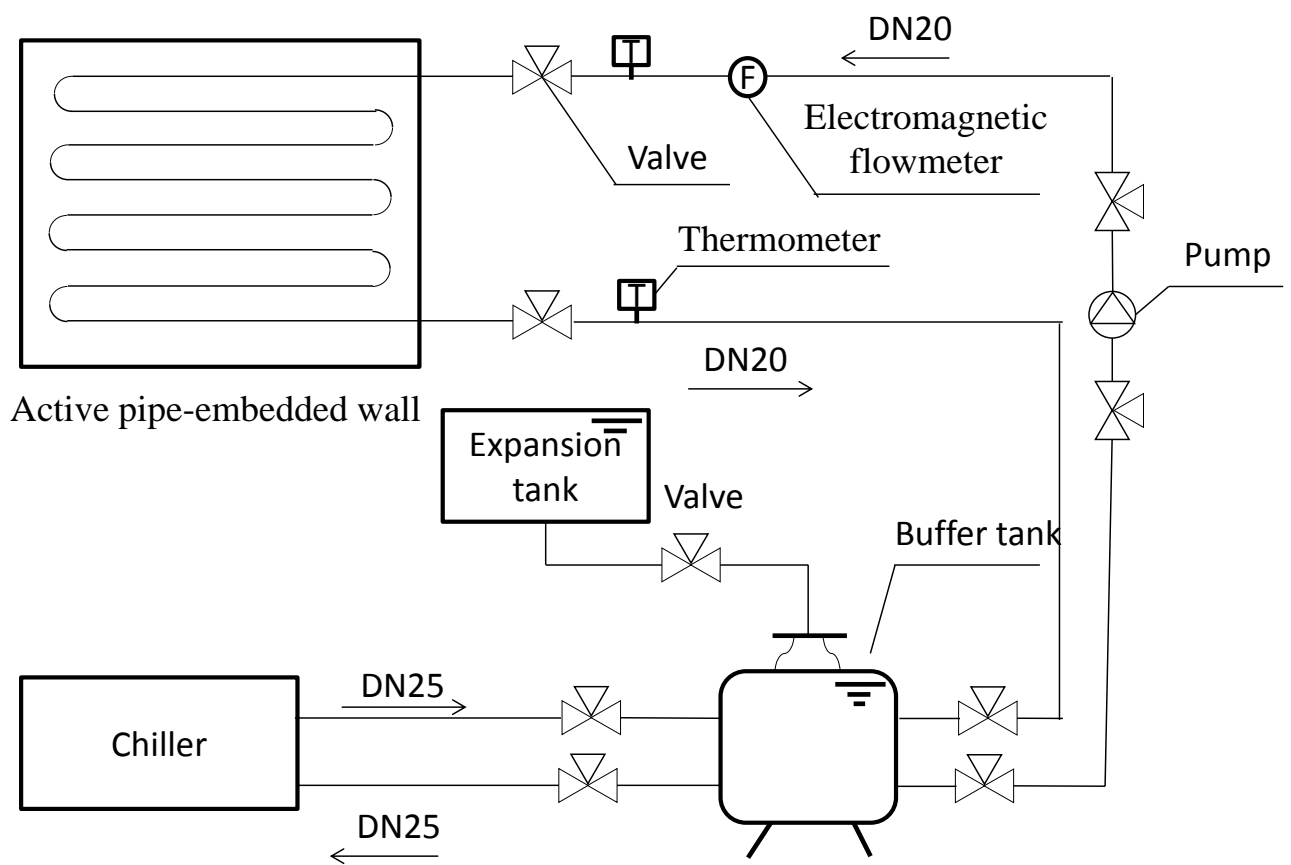

Figure 6 Diagram of the cooling water system for the pipe-embedded structure

\subsection{Environment control system design}

It is of importance to accurately control the air temperature of both environment chambers (i.e., heat insulation chambers). Figure 7 shows the flow diagram of the environment control system. Ceramic PTC heater is used for heating both heat insulation chambers to simulate the outdoor/indoor environment respectively. A temperature sensor is placed in the middle of the environment chamber, and the measurement is transmitted to the controller (PI algorithm is used in this controller). The controller compares the measurement and the set value for computing the output signal to track the set value. The controller can regulate its PI parameters automatically. The control signal from the controller is used as the input for the silicon controlled regulator (i.e., SCR) to control the heat output of the ceramic PTC heater for controlling the air temperature of the environment chamber at the set value. 


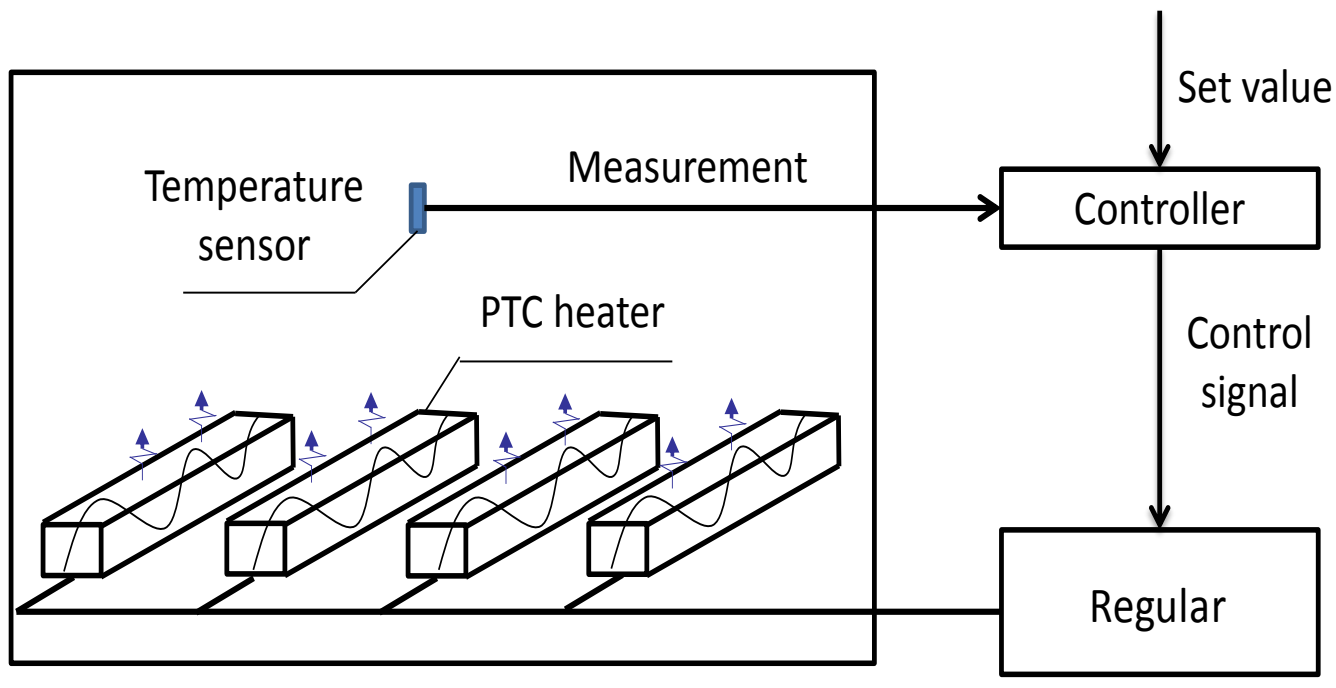

Chamber

Figure 7 Flow diagram of the environment control system

\subsection{Measurement system}

In this experiment, many sensors or meters are installed for measurement. RTD temperature sensors are used to measure the internal/external surface temperature of the active pipe-embedded building wall. Plug-in-type RTD temperature sensors are used for the measurement of the tank water temperature, the inlet and outlet water temperatures of the embedded pipe. 16 temperature sensors are evenly installed on the external and internal surfaces of the wall respectively as shown in Figure 8 (a) and (b). Air temperature of the heat insulation chamber is also monitored. Heat flow meters are pasted on the surface to measure the heat flux of the internal/external surface of the wall as shown in Figure 8 (c). An electromagnetic flowmeter is used to measure the water flow rate through the embedded pipe. The detailed parameters of the measurement devices are given in Table 3. Agilent data acquisition unit 34970A and 34972A are used for data acquisition.

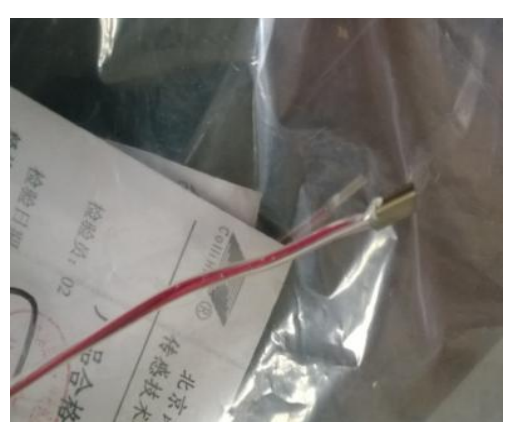

(a)

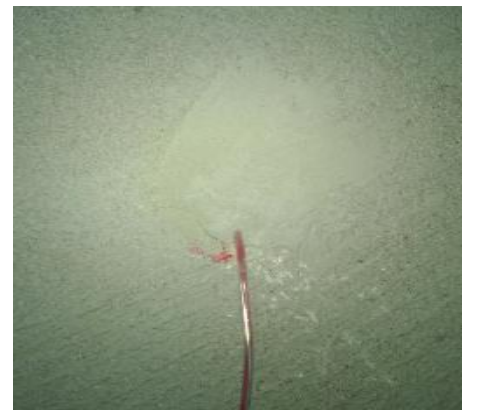

(b)

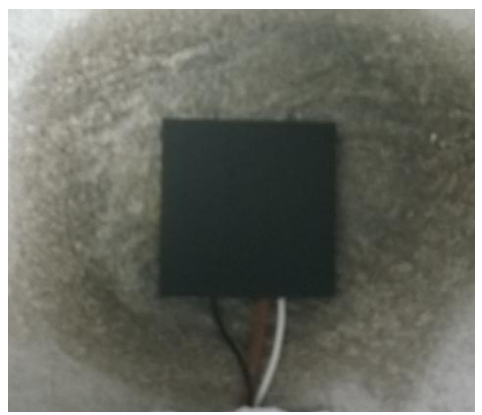

(c) 
281 Table 3 Details of measurement devices

282

283

284

285

286

287

\begin{tabular}{|c|c|c|c|c|}
\hline Description & Type & Number & Range & accuracy \\
\hline Tempearature sensor & PT100/JWB,Surface-mounted & 36 & $0-100^{\circ} \mathrm{C}$ & $\pm 0.1^{\circ} \mathrm{C}$ \\
\hline Tempearature sensor & PT100/K1402008,Plug-in & 3 & $0-100^{\circ} \mathrm{C}$ & $\pm 0.1^{\circ} \mathrm{C}$ \\
\hline Heat flow-meter & WYP/23.26W/mv,Surface-mounted & 12 & - & $\leqslant 5 \%$ \\
\hline Electromagnetic flowmeter & KTLDE-20 & 1 & - & $\pm 0.3 \%$ \\
\hline
\end{tabular}

\section{Analysis of the semi-steady state of the experimental data}

The experiment test rig of the active pipe embedded building envelope sample is used to measure the heat transfer performance of this structure and validate the semi-dynamic model of this structure. The model validation includes two parts. One is to validate the semi-steady thermal performance prediction of the semi-dynamic model, and the other is to validate the pure thermal dynamic performance prediction of this model (Validation is presented in Part 5.). For the validation of the semi-steady performance prediction of this semi-dynamic model, the stability analysis is of importance. It may ensure that the predicted thermal performance of the semi-dynamic model can be compared with the measured thermal performance based on the same boundary condition.

\subsection{Measured boundary conditions}

These two heat insulation chambers are used to simulate typical outdoor environment and indoor environment of Wuhan respectively. In this study, a typical solar-air temperature profile on the southern wall in summer season of Wuhan (a typical hot summer and cold winter region in China) is shown in Figure 9. The air temperature of the outdoor environment chamber is assumed to be the solar-air temperature since there is not artificial sunlight to emulating the solar radiation on the external surface of the pipe-embedded building envelope sample. The indoor air temperature profile is also shown in Figure 9. The solar-air temperature profile and the indoor air temperature profile are used as the set points, and the controllers of both environment chambers control their temperature at their set points respectively. 


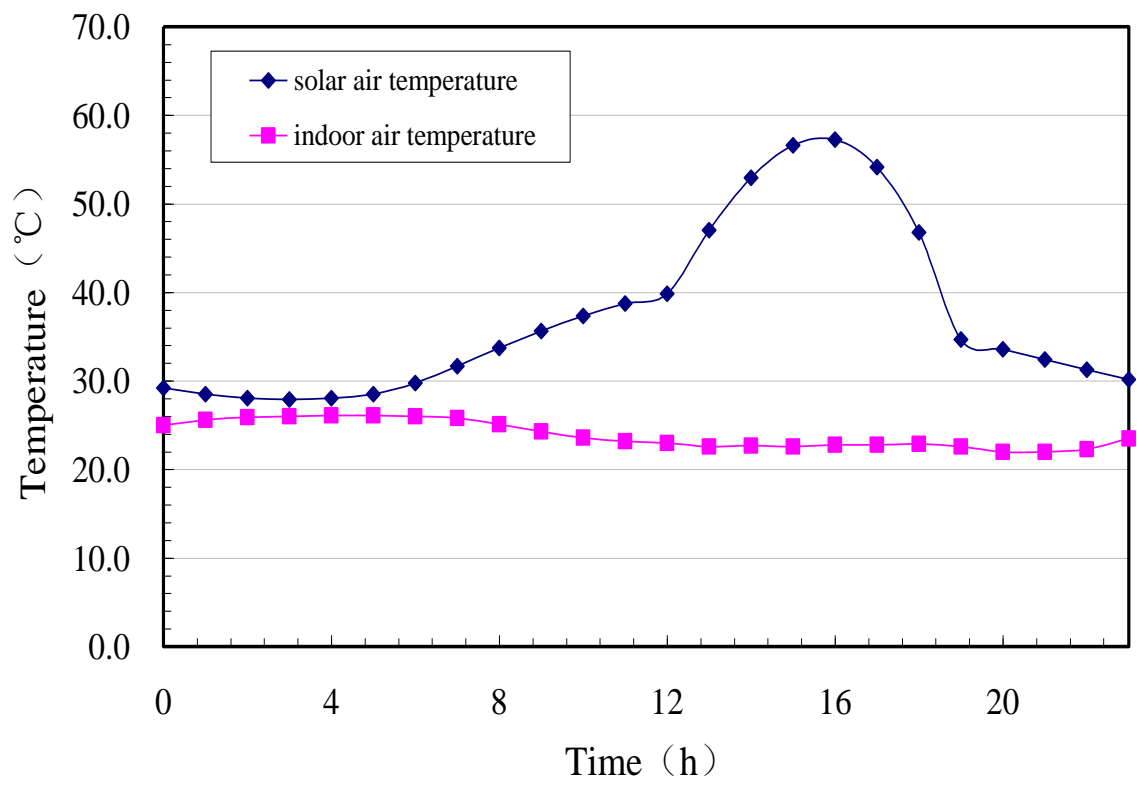

Time (h)

Figure 9 The solar-air temperature and indoor air temperature profiles of a typical summer day in Wuhan

The air temperature is measured by the RTD temperature sensors installed in the middle of the environment chamber and recorded by data acquisition system. In order to guarantee the semi-steady state and accuracy of the experimental result, one experimental period is almost about one week. During the experiment process, the typical outdoor/indoor temperature profiles of both chambers are used the set point profiles respectively and repeated daily. Figure 10 shows that the set point profiles and the measured air temperature profiles of the indoor/outdoor environment chambers in one experimental period (i.e., 7days). Figure 10 (a) shows that the measured air temperature profile of the outdoor environment chamber agrees very well with the set point profile. Figure 10 (b) shows that the measured air temperature of the indoor environment chamber matches the set point well during most of the time. From 9:00 to 21:00, the measured air temperature is higher than the set point. During this period, the output control signal of the controller is zero, and the heat output of the ceramic PTC heater is also zero. Even so, the difference is only about $1.3^{\circ} \mathrm{C}$. Therefore, it can be said that this experiment rig can simulate the outdoor environment and indoor environment very well.

Figure 10 also shows that the measured daily air temperature is almost the same from the fourth day. The judge criterion is that the temperature profile in the present day is the same as that in the previous day. Then, it can be said the boundary conditions of the air temperatures of the outdoor environment chamber and the indoor environment chamber 
reach a semi-steady state.
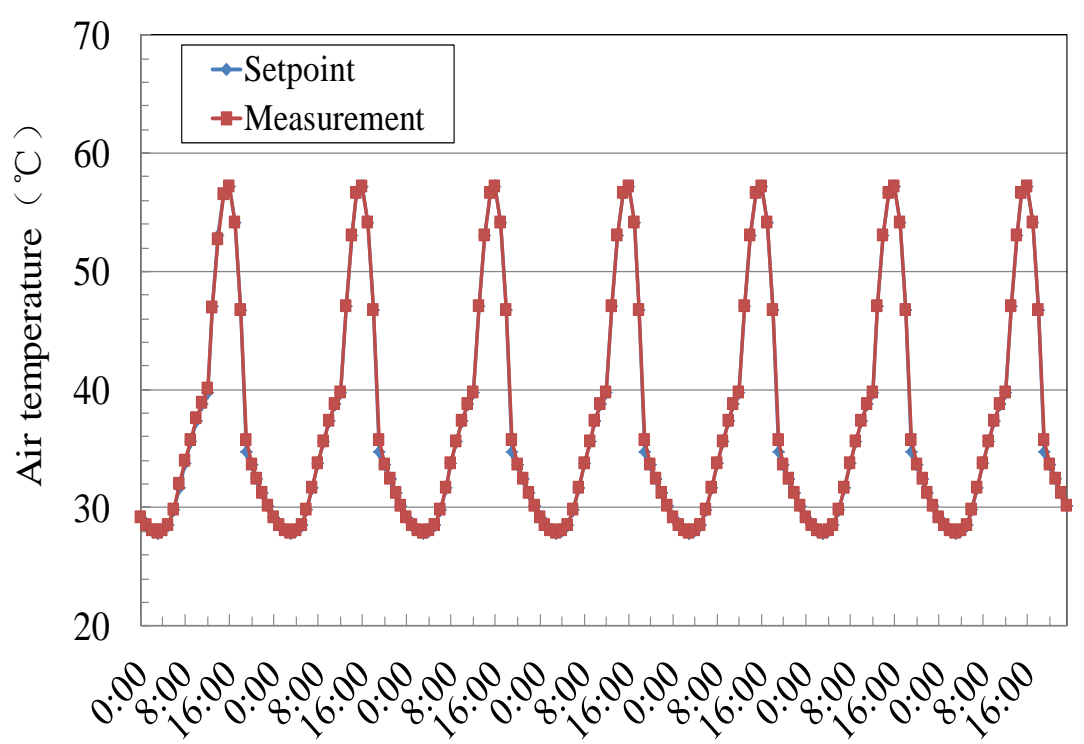

Time (h)

(a) outdoor environment chamber

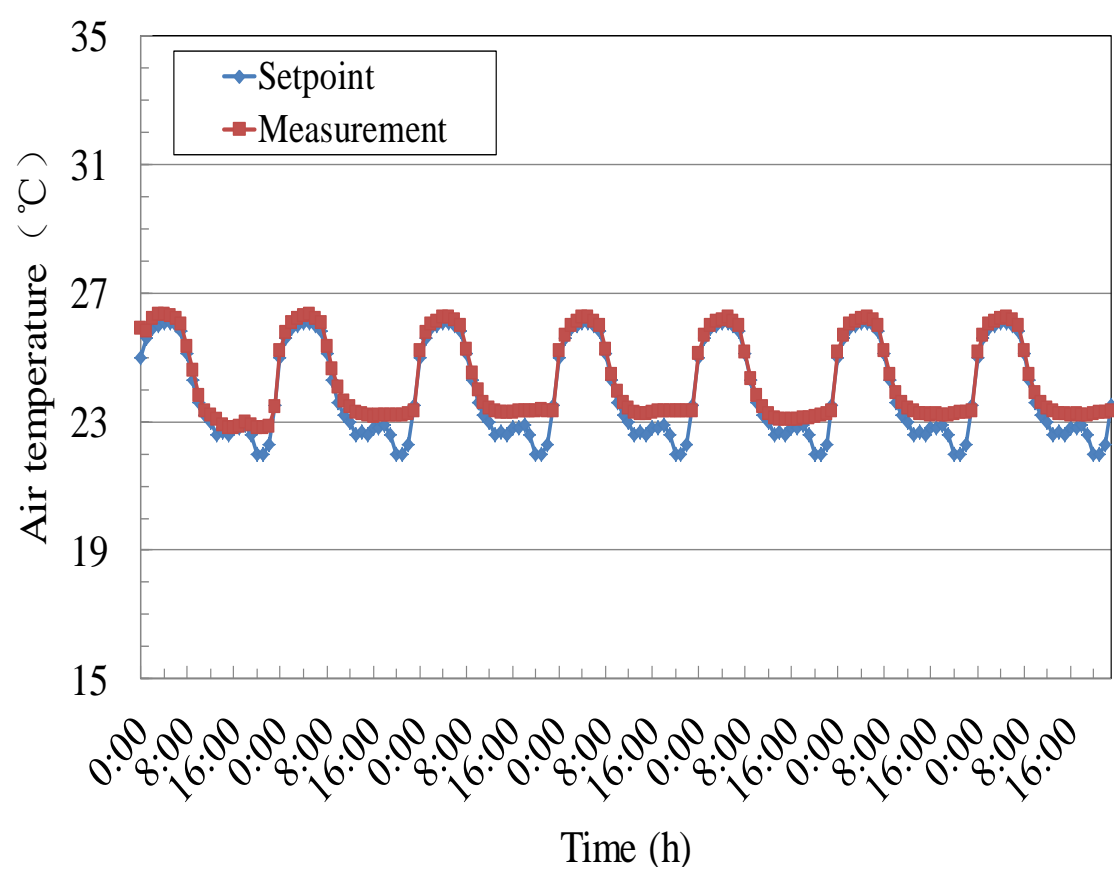

(b)

Figure 10 The measured air temperature and set point profiles of both environment chambers (a) outdoor environment chamber, (b) indoor environment chamber

Figure 11 shows the inlet water temperature profile of the active pipe-embedded building envelope sample during the experimental period (i.e., 7days). It shows that the inlet water temperature almost keeps constant in these 7 days, and the experiment environment of the water system can meet the experimental requirements. 


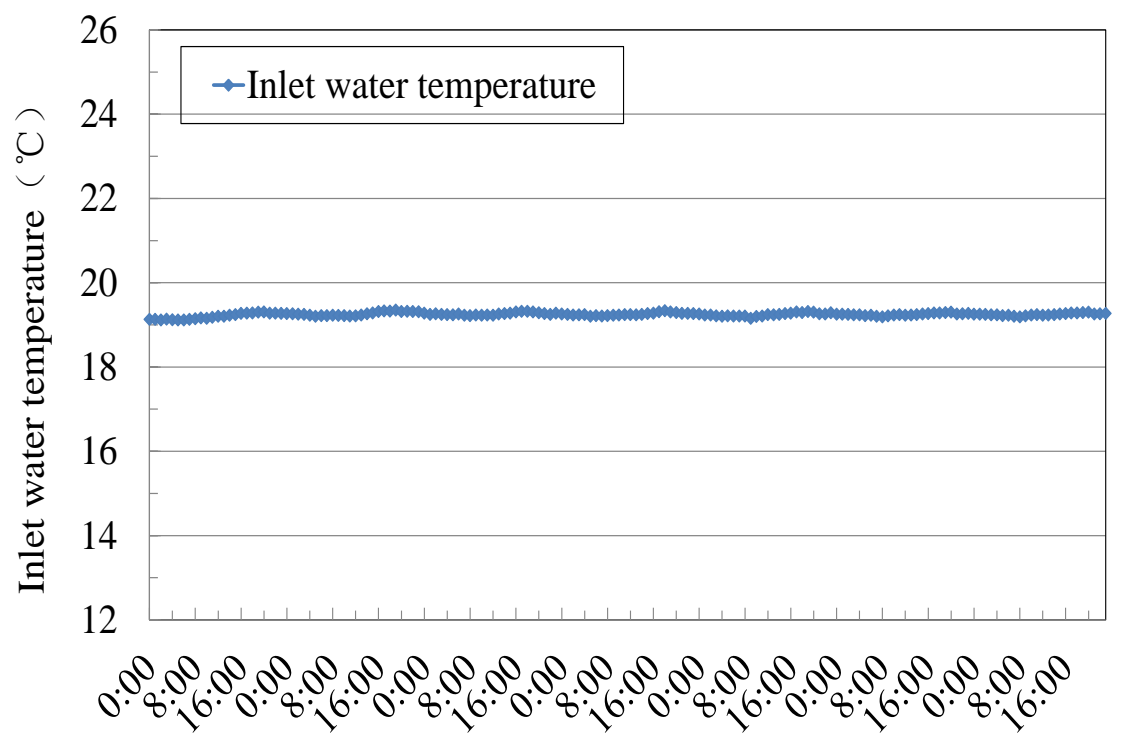

Time (h)

Figure 11 The inlet water temperature profile of the test sample

\subsection{Measured thermal performance}

341 The measured thermal performance of the active pipe-embedded building envelope sample are the temperatures and heat fluxes on both external and internal surfaces of the sample, the outlet water temperature from the embedded pipe, and the water flow rate. In this experiment, the water flow rate is kept constant. The surface temperature is the average of all the measurement points on the external surface or internal surface. The heat flux is also the average of all the measurement points on the external surface or internal surface.

Figure 12 (a)-(c) show the internal surface temperature and the external surface temperature profiles of the sample and the outlet water temperature profile from the embedded pipe during the experimental period (i.e., 7days). The results show that these profiles reach a semi-steady state in the fourth day, and they repeats afterward. As the experiment reaches a semi-steady state, the measured data can be used to analyze the semi-steady thermal performance and validate the semi-dynamic model. 


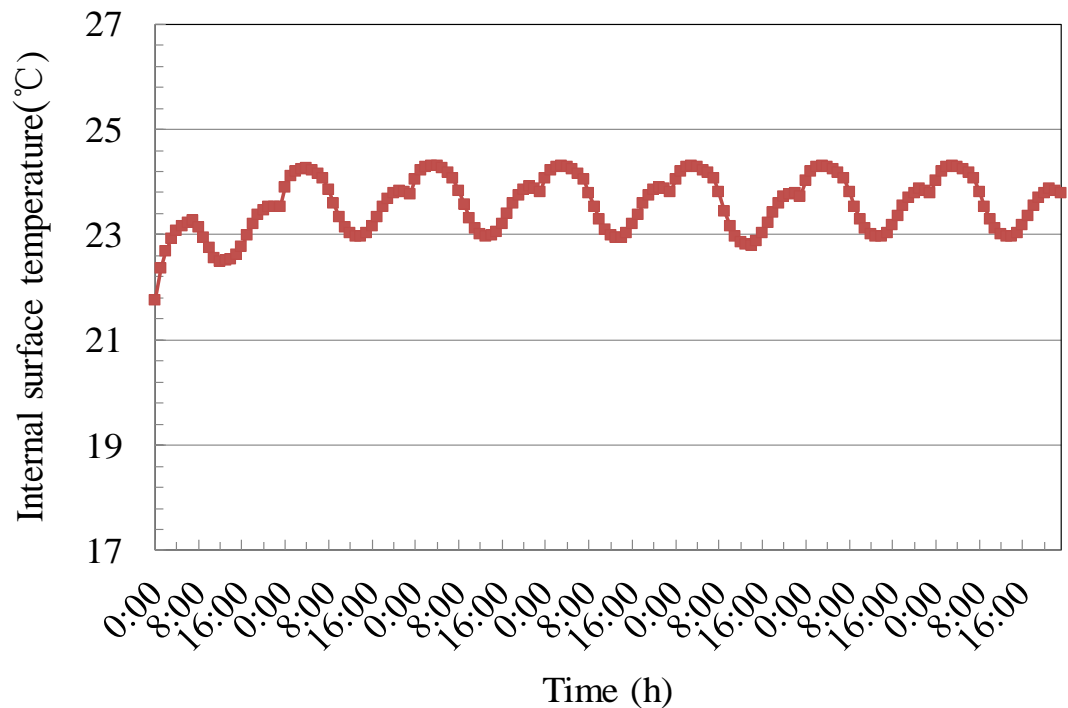

(a)
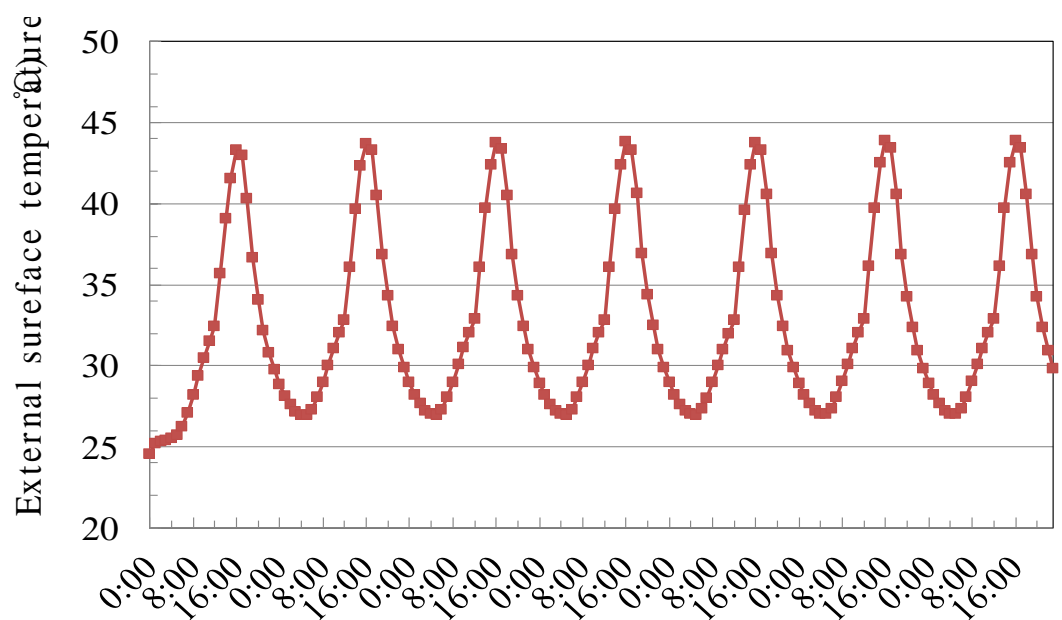

Time $(h)$

(b)

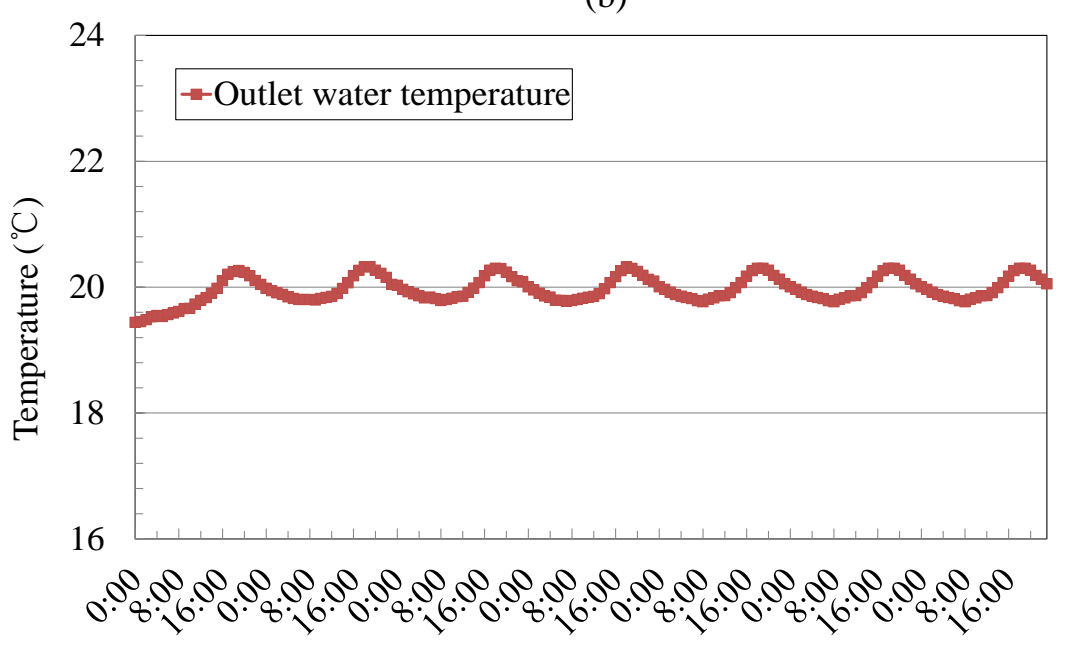

Time (h)

(c)

Figure 12 Both surface temperature profiles and outlet water temperature profile of the sample (a) Internal surface, (b) External surface, (c) Outlet water 
The boundary conditions of the semi-dynamic model and experiment rig should be specified in advance to obtain the thermal performance of the active pipe-embedded building sample. In this study, the typical solar-air temperature profile and indoor air temperature profile in a summer day of Wuhan as shown in Figure 9 are used as the set point profiles for the outdoor environment chamber and the indoor environment chamber respectively. Figure 10 presents the comparison of the practically measured air temperature profiles of both chambers with the corresponding set point profiles. The measured profile can match the set point profile well. This indicates this experiment test rig can simulate the specified outdoor environment and indoor environment accurately. The measured semi-steady boundary conditions are used as the boundary conditions of the semi-dynamic model for calculation.

As said above, the model validation includes two phases. The first phase is to validate the semi-steady thermal performance prediction of the semi-dynamic model, and the second phase is to validate the pure thermal dynamic performance prediction of this model. For validating the pure thermal dynamic performance prediction of this model, the boundary condition is changed suddenly to continue this experiment just after the first phase and this boundary condition repeats until the experiment reaches a new semi-steady state.

The semi-dynamic model is the coupled model of the RC model and the NTU model. The validation of the RC model is not duplicated here for space saving since it is presented detailed in the Ref. [30]. The area of the active pipe-embedded building envelope sample for the experiment is $7.92 \mathrm{~m}^{2}$. The total resistance and capacitance of this structure are $0.053 \mathrm{~K} \cdot \mathrm{W}^{-1}$ and $4911752 \mathrm{~J} \cdot \mathrm{K}^{-1}$ based on Table 2 . The identified parameters of the RC model are listed in Table 4.

Table 4 Identified parameters of the RC model of the active pipe-embedded building envelope

\begin{tabular}{ccccccccccc}
\hline & \multicolumn{8}{c}{ Parameters of resistance, $\mathrm{R}\left(\mathrm{K} \cdot \mathrm{W}^{-1}\right)$, and capacitance, $\mathrm{C}\left(\mathrm{J} \cdot \mathrm{K}^{-1}\right)$} \\
\cline { 2 - 10 } & $\mathrm{R}_{1}$ & $\mathrm{R}_{2}$ & $\mathrm{R}_{3}$ & $\mathrm{R}_{4}$ & $\mathrm{R}_{5}$ & $\mathrm{C}_{1}$ & $\mathrm{C}_{2}$ & $\mathrm{R}^{*}$ & $\mathrm{C}^{*}$ \\
\hline$R C$ model & 0.009 & 0.078 & 0.030 & 0.030 & 0.009 & 1824260 & 1824260 & 0.052 & 3648520 \\
\hline $\mathrm{R}^{*}, \mathrm{C}^{*}$ are the calculated total resistance and capacitance based on the identified parameters
\end{tabular}

Based on the experiment data, the heat transfer performance of the active pipe-embedded building envelope sample is used to validate the semi-dynamic model of 
this structure. To validate the accuracy of the semi-dynamic model of this structure, the external wall surface heat flux, the internal wall surface heat flux and the outlet water temperature measured and predicted by the experiment rig and the semi-dynamic model respectively are used as indicators for comparison.

\subsection{Semi-steady thermal performance validation}

The heat transfer performances with different water velocities and inlet temperature of the water have been tested. One case is presented to validate the semi-steady thermal performance prediction of the semi-dynamic model of this sample. In this case, the velocity of the water is $0.5 \mathrm{~m} / \mathrm{s}$ for allowing turbulent flow. The inlet water temperature is $18^{\circ} \mathrm{C}$. The outdoor and indoor air temperature profiles are shown in Figure 10. The boundary conditions were the same until the experiment reaches a semi-steady state boundary condition. The semi-steady thermal performance of the active pipe-embedded building envelope sample can be predicted by the semi-dynamic model and be measured by the experiment.

Figure 13 presents the outlet water temperature profiles measured by the experiment rig and predicted by the semi-dynamic model respectively in a semi-steady state in one day. The absolute average error is $0.06^{\circ} \mathrm{C}$. From 18 o'clock to 23 o'clock, marginal deviation may be observed as shown as Figure 13. The maximum absolute error between the measured value and the calculated value is less than $0.15^{\circ} \mathrm{C}$. A possible explanation may be that the temperature changes quickly from 13 o'clock to 18 o'clock as shown in Figure 10, and an obvious thermal inertia exists in the active pipe-embedded building envelope sample. The outlet water temperature predicted by the semi-dynamic model agrees well with that measured by the experiment rig although marginal deviation may be observed. 
600

Figure 13 The outlet water temperature profiles by experimental measurement and model prediction in one day $\left(\mathrm{v}=0.8 \mathrm{~m} / \mathrm{s}, \mathrm{T}=18^{\circ} \mathrm{C}\right)$

The heat flux taken away by the water measured by the experiment rig is calculated based on the measured water flow rate and the outlet and inlet water temperature. Figure 14 shows the measured heat flux taken away by the water flow and that predicted by the semi-dynamic model at a semi-steady state in one day. Similar phenomenon could be observed as Figure 13 since the quickly changed outdoor air temperature and the thermal inertia.

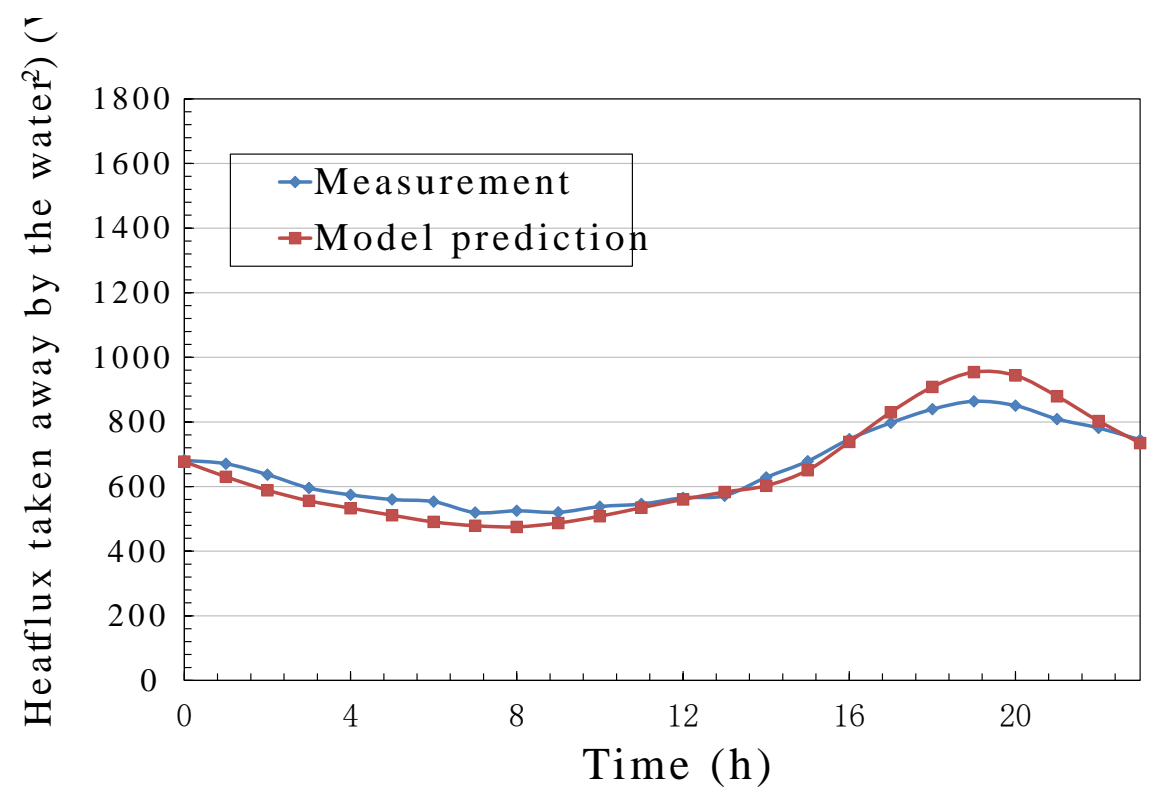


Figure 14 The heat flux taken away by experimental measurement and model prediction in one day $\left(\mathrm{v}=0.8 \mathrm{~m} / \mathrm{s}, \mathrm{T}=18^{\circ} \mathrm{C}\right)$

Except the outlet water temperature and the heat flux taken away by the water, the external wall surface heat flux and internal wall surface heat flux are also used for performance comparison. Weber et al. [23] states that the accuracy of the heat flow meter in most experiment rig may be not high without performing a very sophisticated analysis including filtering and other signal processing techniques, and the very sophisticated analysis is very expensive and complicate. Therefore, the external wall surface heat flux and internal wall surface heat flux are only used as supplementations.

Figure 15 and 16 present external wall surface and internal wall surface heat flux profiles measured by the experiment rig and predicted by the semi-dynamic model respectively in one day. The average relative error in predicting the external wall surface is $16 \%$, and the relative error in predicting the total external wall surface heat flux in one day is only $7 \%$. Larger relative error may be observed, about $50 \%$, when the heat flux is very small at 20 o'clock. As shown in Figure 16, the negative internal surface heat flux indicates the internal wall surface temperature is lower than the indoor air temperature, and the wall surface absorbs heat from the indoor air. The positive internal surface heat flux means that the heat is released from the internal wall surface into the indoor air. Figure 16 shows that the measured value is higher than the calculated value although the trend of both curves is similar. The reason may be that the measured signal of the internal surface heat flux is very small and at the low range of the heat flux meter which results in large error. The signal output is at the microvolt level. 


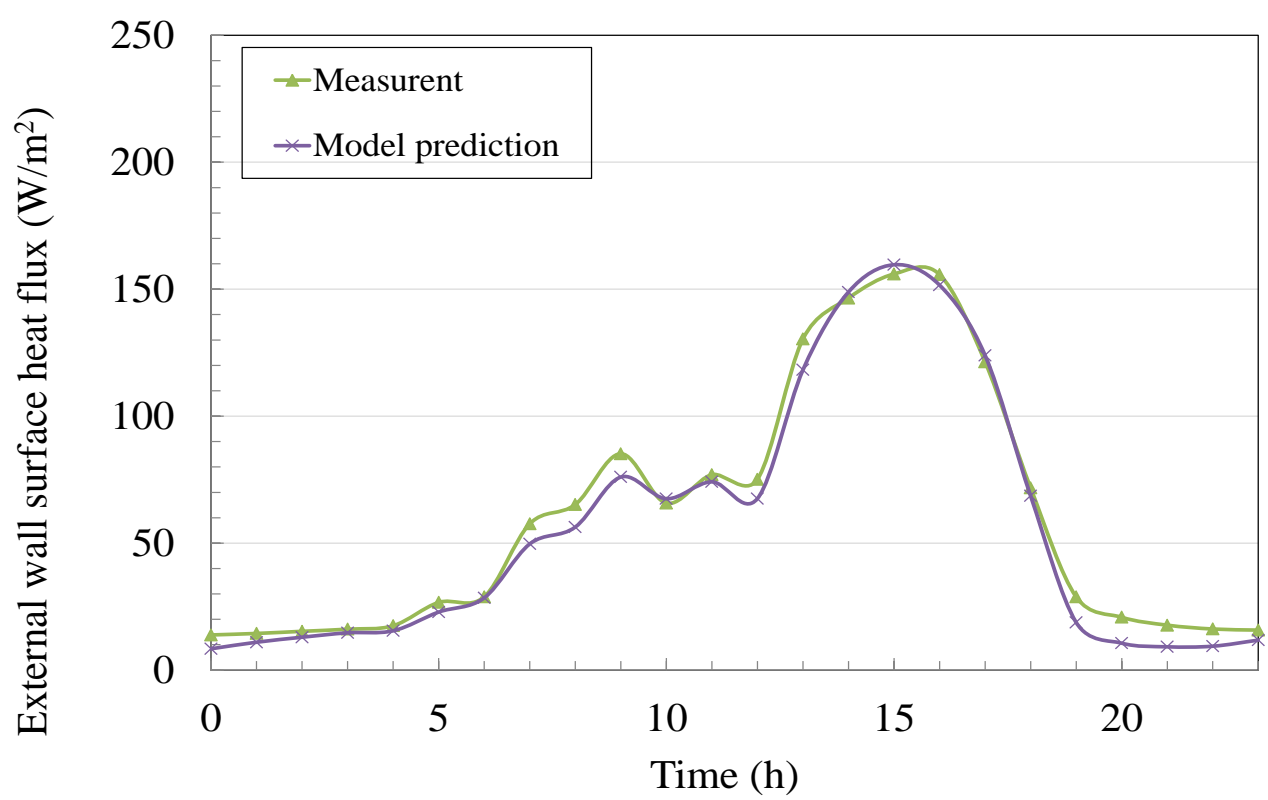

Figure 15 The measured and predicted external surface heat flux profiles in a semi-steady state in one day $\left(\mathrm{v}=0.8 \mathrm{~m} / \mathrm{s}, \mathrm{T}=18^{\circ} \mathrm{C}\right)$

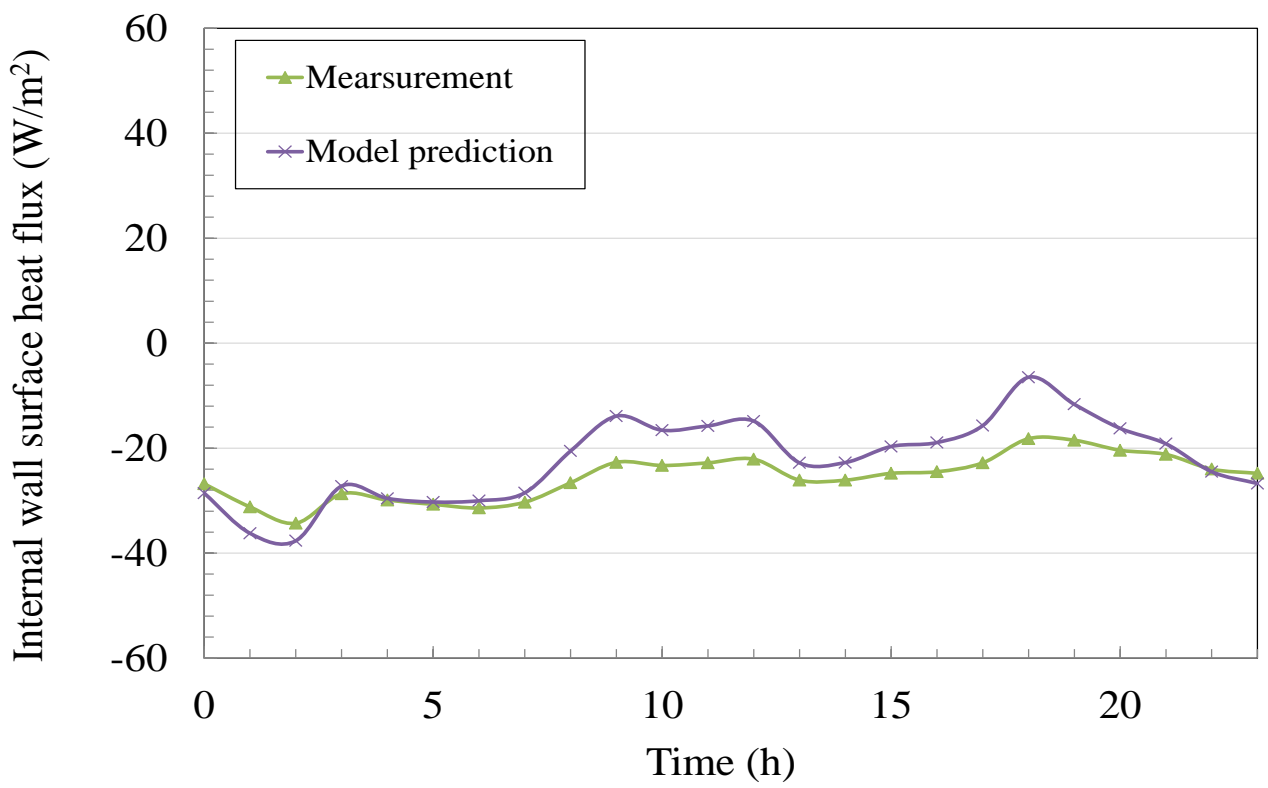

Figure 16 The measured and predicted internal surface heat flux profiles in a semi-steady state in one day $\left(\mathrm{v}=0.8 \mathrm{~m} / \mathrm{s}, \mathrm{T}=18^{\circ} \mathrm{C}\right)$

The total heat transfer of the external wall surface, internal wall surface and the heat flux taken away by the water in a semi-steady state in one day can be easily calculated 456 based on measurement and model prediction. The detailed data is summarized in Table 5. 457 This table shows that the imbalance between the total heat taken away by the water and sum of the heat flux on both surfaces predicted by the semi-dynamic model is very small, 
about $0.2 \%$. The imbalance between the total heat taken away by the water and sum of the heat flux on both surfaces based on the measurement is about $2.0 \%$. This is due to the insufficient accuracy of these measurement devices, such as heat flux meter, temperature sensor and water flow meter.

Table 5 Details of the total heat transfer by measurement and model prediction in a semi-steady state in one day

\begin{tabular}{|c|c|c|c|c|c|}
\hline \multicolumn{2}{|c|}{ Description } & $\begin{array}{c}\text { External wall heat } \\
\text { flux (MJ) }\end{array}$ & $\begin{array}{c}\text { Internal wall heat } \\
\text { flux (MJ) }\end{array}$ & $\begin{array}{c}\text { Heat flux taken away } \\
\text { by the water (MJ) }\end{array}$ & Error(\%) \\
\hline \multirow{2}{*}{$\mathrm{v}=0.5 \mathrm{~m} / \mathrm{s}$, Tin=18 ${ }^{\circ} \mathrm{C}$} & Experimental data & 41 & -16.5 & 56.4 & 2.0 \\
\cline { 2 - 6 } & Semi-dynamical model & 38.1 & -18.9 & 56.9 & 0.2 \\
\hline
\end{tabular}

\subsection{Dynamic thermal performance validation}

To validate the pure dynamic performance prediction of the semi-dynamic model, further experiments were performed. The outdoor and indoor air temperature profiles are the same as the case presented in Section 5.1 , the water velocity $0.8 \mathrm{~m} / \mathrm{s}$ and the inlet water temperature $18^{\circ} \mathrm{C}$ are also the same as the case presented in Section 5.1. After 6 repeats (i.e., 6 days), the experiment reached a semi-steady state boundary condition and a semi-steady state of the pipe-embedded building envelope sample (i.e., the first phase experiment). Then, the water flow rate and the inlet water temperature changed suddenly to introduce a step disturbance to this experiment while the outdoor and indoor air temperature profile still kept the same. The water velocity was changed suddenly from $0.8 \mathrm{~m} / \mathrm{s}$ to $0.5 \mathrm{~m} / \mathrm{s}$, and the inlet water temperature was changed suddenly from $18^{\circ} \mathrm{C}$ to $19^{\circ} \mathrm{C}$. After three or four days, the pipe-embedded building envelope sample reached a new semi-steady state (i.e., the second phase experiment). Between both semi-steady states, the pipe-embedded building envelope sample underwent a pure dynamic process.

To predict the pure dynamic performance of this sample by using the semi-dynamic model, the initial state of this model should be specified to be close experiment state for facilitate the comparison between the measurement and model prediction. The initial state of the semi-dynamic model is indicated by the node temperature $T_{1}$ and $T_{2}$ in the RC model. Both values are the calculated node temperature at the end the last repeat of the first phase experiment. The initial values are used for the dynamic performance prediction of the semi-dynamic model for the second phase experiment. 
Only the thermal performance of the first three day of the second phase experiment is presented for analysis since the semi-steady state reached basically in the second/three day. Figure 17 shows the measured outlet water temperature and the predicted outlet water temperature by using the semi-dynamic model. In the first day, the thermal process is typically dynamic. The difference between the experimental measurement and the model prediction is very small. The average absolute errors in these three days are $0.09^{\circ} \mathrm{C}$, $0.08^{\circ} \mathrm{C}$ and $0.10^{\circ} \mathrm{C}$ respectively. Figure 18 shows the measured heat flux taken away by the water and the predicted heat flux by the model. Both profiles agree well although noticeable deviation may be observed. The average relative errors are about $11 \%$ for those three days. Figure 19 presents external wall surface heat flux profiles measured by the experiment rig and predicted by the semi-dynamic model from dynamic to semi-dynamic state respectively. The average relative errors are $12 \%, 12 \%$ and $11 \%$ in these three days respectively. The relative errors in predicting the total external wall surface heat flux in one day are $6 \%, 8 \%, 10 \%$ in these three days respectively.

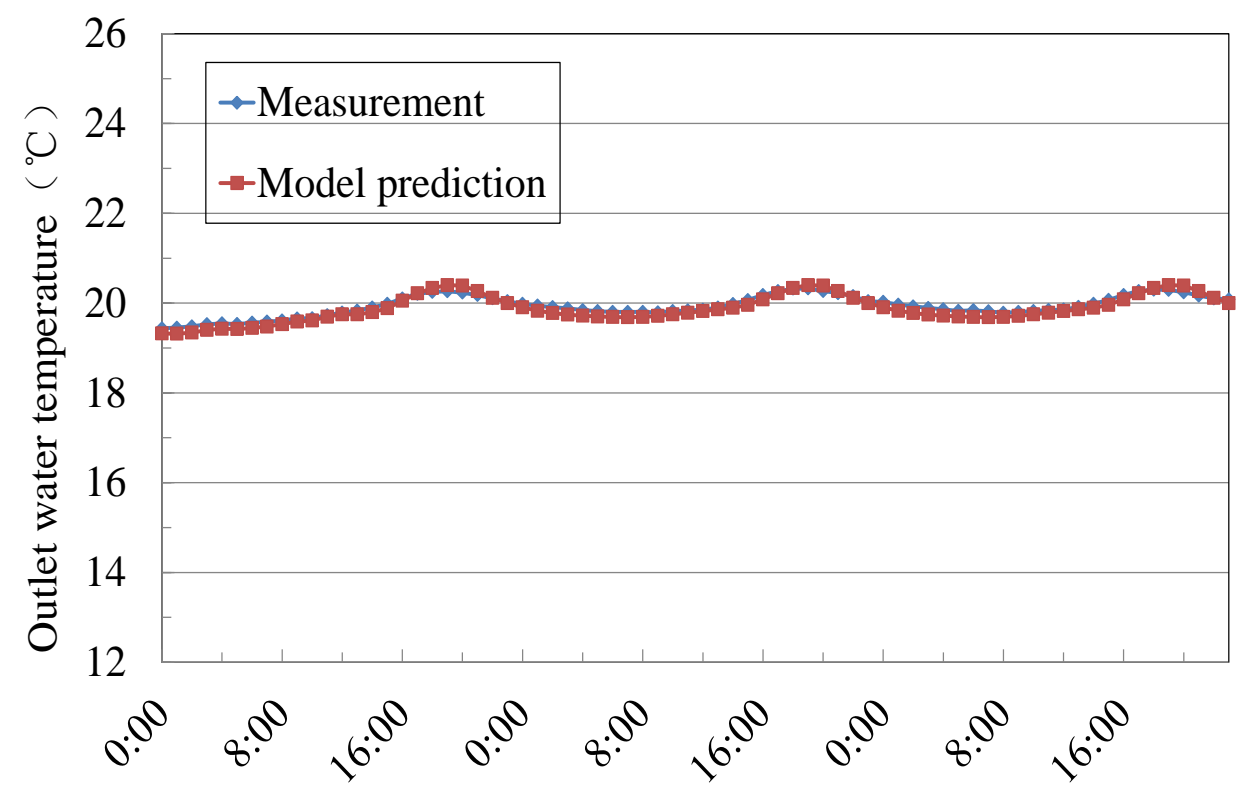

Figure 17 The measured and predicted outlet water temperature profiles $(\mathrm{v}=0.5 \mathrm{~m} / \mathrm{s}$, $\left.\mathrm{T}=19^{\circ} \mathrm{C}\right)$ 


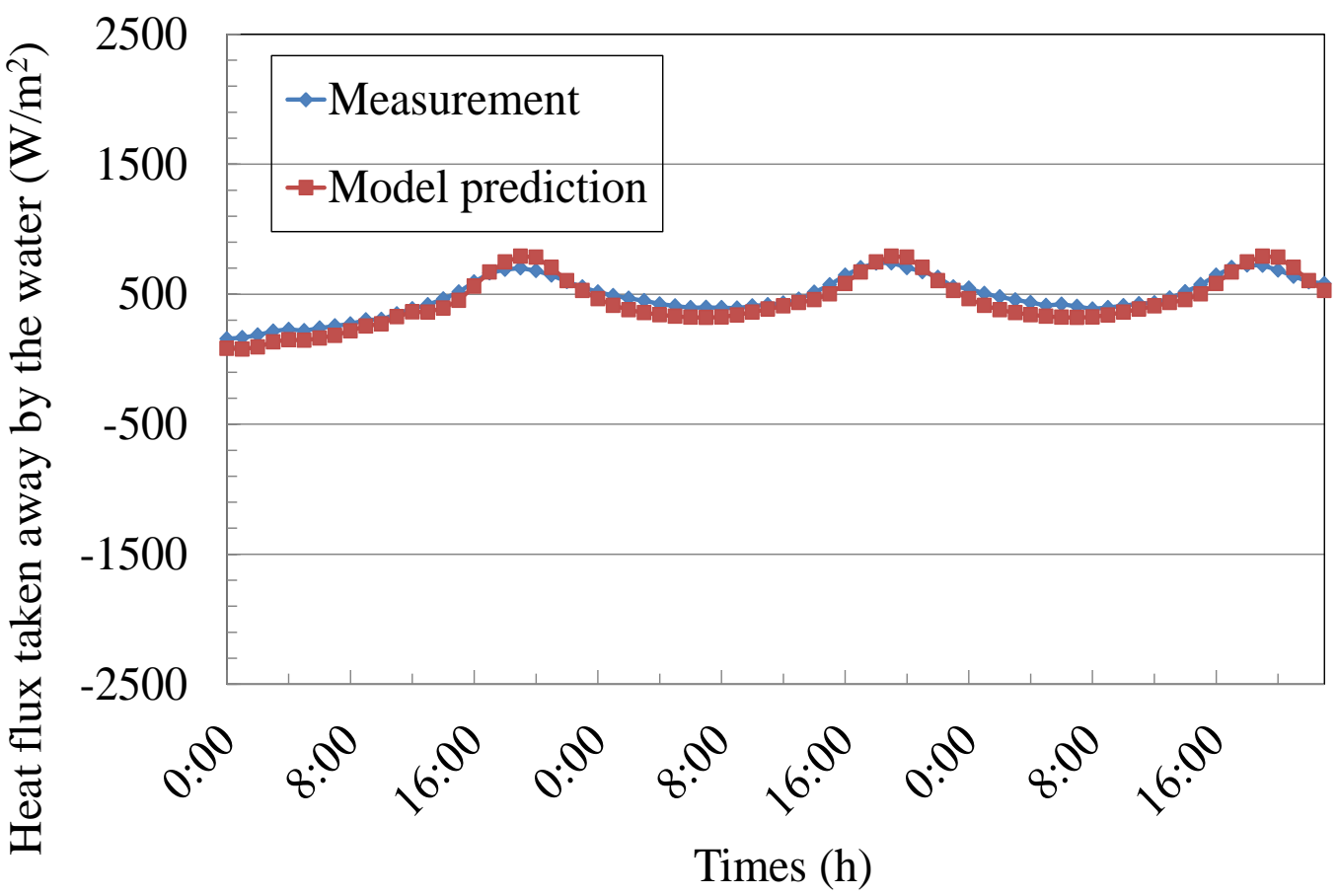

Figure 18 The measured and predicted heat flux taken away by the water $(\mathrm{v}=0.5 \mathrm{~m} / \mathrm{s}$,

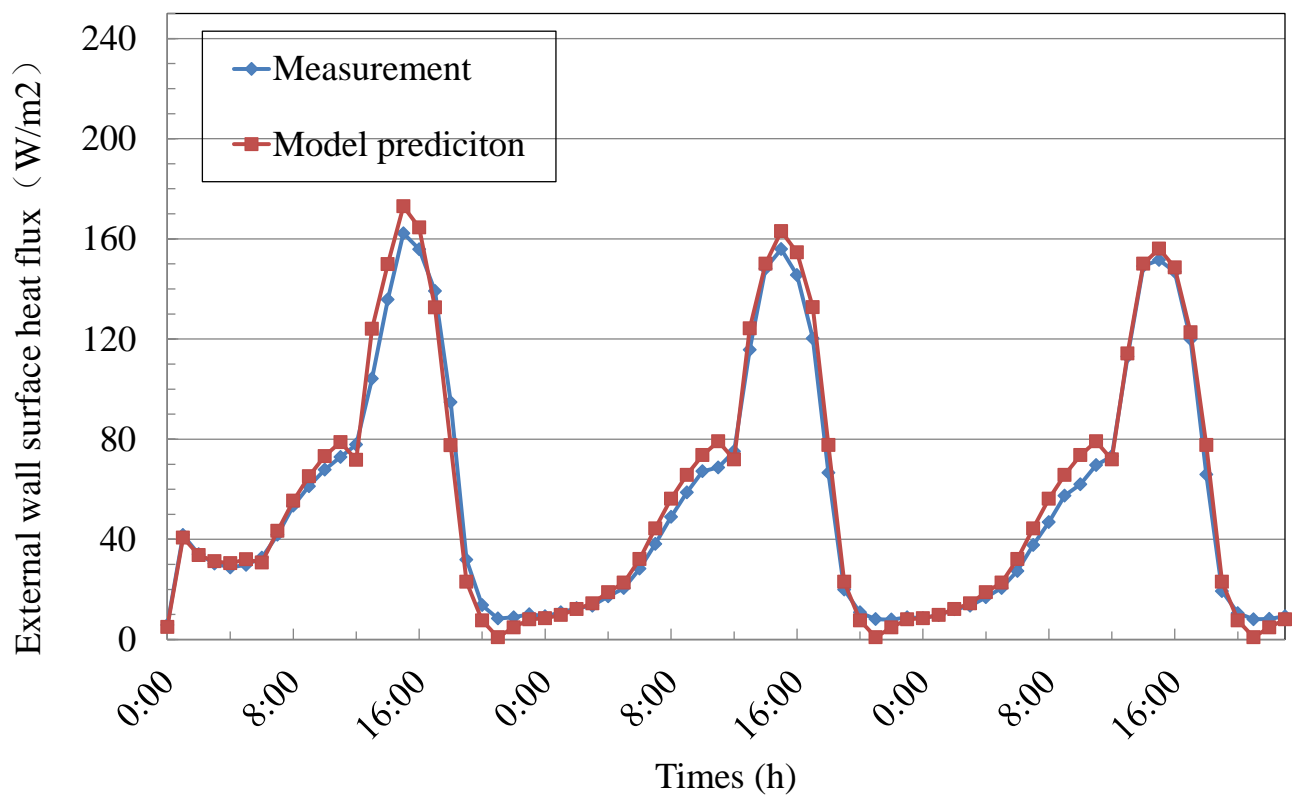

Figure 19 The measured and predicted external wall surface heat flux profiles$$
\left(\mathrm{v}=0.5 \mathrm{~m} / \mathrm{s}, \mathrm{T}=19^{\circ} \mathrm{C}\right)
$$

Table 6 shows the total heat transfers on the external wall surface and internal wall surface and the heat taken away by the water in these three days. In the first day, the heat taken away by the water is far less than the sum of the heat transfers on the external wall 
surface and the internal wall surface. This indicated it is a pure dynamic process in the first day and obvious thermal storage exists in the active pipe-embedded building envelope sample. In the following two days, the relative error between the heat taken away by the water and the sum of the heat transfers on the external wall surface and the internal wall surface is very small. It indicates that the sample reaches a semi-steady state in the second day.

Table 6 Details of total heat transfer of different surfaces in different days

\begin{tabular}{|l|c|c|c|c|c|}
\hline \multirow{2}{*}{} & Description & $\begin{array}{c}\text { External wall heat } \\
\text { flux (MJ) }\end{array}$ & $\begin{array}{c}\text { Internal wall heat } \\
\text { flux (MJ) }\end{array}$ & $\begin{array}{c}\text { Heat flux taken away } \\
\text { by the water (MJ) }\end{array}$ & Error(\%) \\
\hline \multirow{2}{*}{ First day } & Experimental data & 41.1 & -9.7 & 35.3 & 43.9 \\
\cline { 2 - 6 } & Prediction of Semi-dynamical model & 38.8 & -5.9 & 32.6 & 37.1 \\
\hline \multirow{2}{*}{ Second day } & Experimental data & 36.4 & -6.5 & 45.2 & 5.1 \\
\cline { 2 - 6 } & Prediction of Semi-dynamical model & 39.6 & -2.4 & 41.6 & 1.0 \\
\hline \multirow{2}{*}{ Third day } & Experimental data & 35.8 & -6.5 & 45.3 & 6.6 \\
\hline & Prediction of Semi-dynamical model & 39.6 & -2.4 & 41.6 & 1.0 \\
\hline
\end{tabular}

Based on above analysis and validation, the semi-dynamic model of the pipe-embedded building envelope can predict the thermal performance well including the outlet water temperature, total heat flux taken away by the water and the surface heat flux etc. whenever this active building envelope is in a semi-steady state or in a pure dynamic state different from the semi-steady state. This model is simple with the form of resistance, capacitance, and $N T U$, and very easy to be solved. It can be integrated in conventional simulation software such as EnergyPlus or TRNSYS for simulating the thermal performance and energy performance of buildings which utilize this active pipe-embedded building envelope.

\section{Conclusion}

This paper presents the experiment setup and experimental validation of a semi-dynamic simplified model of active pipe-embedded building envelopes. The design and establishment of the experimental test rig is successful. The chamber air temperature can be controlled as expected, and the supply can also be controlled constant by the special design of the water system. The heat meter may measure the heat flux on the external surface reasonably although it cannot measure the heat flux on the internal surface accurately. This is due to the fact that the heat flux on the internal surface is small and the measured signal is at the low range of the heat meter and in the microvolt level. 
The experimental validation of this semi-dynamic simplified model of active pipe-embedded building envelopes includes two phases. The first phase is to validate the semi-steady performance prediction of this model. The second phase is to validate its pure dynamic performance prediction. For the validation of the semi-steady performance prediction of this model, the average absolute error in predicting the outlet water temperature is $0.06^{\circ} \mathrm{C}$. The average relative error in predicting the external surface heat flux is $16 \%$ while the relative error for the total external wall surface heat transfer in one day is only $7 \%$. For the validation of the pure dynamic performance prediction of this model, this active pipe-embedded building envelope is in dynamic state only in the first day and reaches a new semi-steady state in the second/third day. The average relative error in predicting the outlet water temperature in the first three days is less than $0.10^{\circ} \mathrm{C}$. The average relative errors in predicting the heat flux taken away by the water the first three days are about $11 \%$.

No matter whether this active pipe-embedded building envelope is in semi-steady state or in pure dynamic state, this semi-dynamic simplified model may predict its thermal performance accurately. This model can predict its dynamic performance since it can capture its dynamics by the capacitance, and this model can calculate quickly since its structure is very simple and easy to be solved. It can be integrated in conventional simulation software, such as EnergyPlus or TRNSYS etc., for the thermal performance and energy performance evaluation for buildings which utilize active pipe-embedded building envelopes and renewable energy sources such as ground water etc.

\section{Acknowledgements}

This work presented in this paper is financially supported by a grant (No. 51178201) of

564 National Science Foundation of China, and supported by the research fund of "Program 565 for New Century Excellent Talents in University" (No. 2011CDB292) and "Specialized Research Fund for the Doctoral Program of Higher Education" (No. 20120142110078) as well as a grant of "the Fundamental Research Funds for the Central Universities" (HUST: 2015QN116).

\section{References}


[2] Zhu Q.Y., Xu X.H., Yu J.H., Study of dynamic thermal performance of active pipe-embedded building envelopes based on frequency-domain finite difference method, in: ASim 2012 IBPSA Asia Conference, Shanghai, Nov. 25-27, 2012.

[3] Bunn R., Thermodeck: the thermal flywheel, Build. Serv. J. 13 (5) (1991) 41-44.

[4] Winwood R., Benstead R., Edwards R., Advanced fabric energy storage I: review, Build. Serv. Eng. Res. Technol. 18 (1) (1997) :1-6.

[5] Braham G.D., Slab cooling and the thermo Deck System, in Low Energy cooling technologies for buildings, p.45-57, IMechE seminar publication, 1988-7, ISBN 1860581579.

[6] Meierhans R.A., Slab cooling and earth coupling, ASHRAE Trans. 99 (2) (1993) 511-518.

[7] Meierhans R.A., Room air conditioning by means of overnight cooling of the concrete ceiling, ASHRAE Trans. 102 (1) (1996) 693-697.

[8] Xu X.H., Wang S.W., Wang J.B. and Xiao F., Active pipe-embedded structures in buildings for utilizing low-grade energy sources: a review, Energy Build. 42 (10) (2010) 1567-1581.

[9] Širokýa J., Oldewurtelb F., Ciglerc J., Prívarac S., Experimental analysis of model predictive control for an energy efficient building heating system, Appl Energy, 88 (9) (2011):3079-3087.

[10]K. Arendt, M. Krzaczek, J. Florczuk. Numerical analysis by FEM and analytical study of the dynamic thermal behavior of hollow bricks with different cavity concentration. Int. J. Therm. Sci., 50 (8) (2011) 1543-1553.

[11]Y. Yao, Z. Lian, S. Liu, et al. Hourly cooling load prediction by a combined forecasting model based on Analytic Hierarchy Process. Int. J. Therm. Sci., 43 (11) (2004) 1107 - 1118.

[12] Olofssona T., Mahlia T.M.I., Modeling and simulation of the energy use in an occupied residential building in cold climate, Appl Energy, 91 (1) (2012):432 -438.

[13]Xu X.H.,Yu J.H., Wang S.W., Wang J.B., Research and application of active hollow core slabs in building systems for utilizing low energy sources, Appl Energy, 116 (2014) $424-435$.

[14]G. Henze, C. Felsmann, G. Knabe, Evaluation of optimal control for active and passive building thermal storage, Int. J. Therm. Sci., 43 (2) (2004) 173-183.

[15] Schnurr N.M., Rogers D.B., Heat transfer design data for optimization of snow melting systems, ASHRAE Trans., vol.76 (2) (1970) 257-263.

[16]Zhang Z., Pate M.B., An experimental study of the transient response of a radiant panel ceiling and enclosure, ASHRAE Transactions, 92 (2A) (1986b) 85-94.

[17]Zhang Z., Pate M.B., A semi-analytical formulation of heat transfer from structures with embedded tubes, in: The 24th National Heat Transfer Conference, ASME-HTD, Pittsburgh, Pennsylvania, August, 78(9-12) (1987) 17-25.

[18] Antonopoulos K.A. Analytical and numerical heat transfer in cooling panels. International Journal of Heat and Mass Transfer, 35(11) (1992) 2771-2782.

[19]Antonopoulos K.A. and Democritou F.. Periodic steady-state heat transfer in cooling panels. International Journal of Heat and Fluid Flow, 14(1) (1993) 94-100. 
[20]Antonopoulos K.A. and Tzivanidis C.. Numerical solution of unsteady three-dimensional heat transfer during space cooling using ceiling-embedded piping. Energy, 22(1) (1997) 59-67.

[21] Koschenz M., Dorer V., Interaction of an air system with concrete core conditioning, Energy Build. 30 (2) (1999) 139-145.

[22] Weber T., Jóhannesson G., An optimized RC-network for thermally activated building components, Build. Environ. 40 (1) (2005a) 1-14.

[23] Weber T., Jo'hannesson G., Koschenz M. et al., Validation of a FEM-program (frequency-domain) and a simplified RC-model (time-domain) for thermally activated building component systems (TABS) using measurement data, Energy and Buildings 37 (2005b):707-724.

[24]Xu X.H., Wang S.W., A simplified dynamic model for existing buildings using CTF and thermal network models, Int. J. Therm. Sci., 47(9) (2008): 1249-1262,

[25]Zhu N., Wang S.W., Xu X.H., Ma Z.J., A simplified dynamic model of building structures integrated with shaped-stabilized phase change materials, Int. J. Therm. Sci., 49 (9) (2010): 1722-1731.

[26]Liu K.X., Tian Z., Zhang C., et al. Establishment and validation of modified star-type RC-network model for concrete core cooling slab. Energy and Buildings 43 (2011) 2378-2384.

[27] Wu X.Z., Zhao J.N., Olesen B.W., et al., A new simplified model to calculate surface temperature and heat transfer of radiant floor heating and cooling systems, Energy and Buildings, 105 (2015) 285-293.

[28]Xie Junlong, Xu Xinhua, Li Anbang, Zhu Qiuyuan, Experimental validation of frequency-domain finite-difference model of active pipe-embedded building envelope in time domain by using Fourier series analysis, Energy and Buildings, 99(2015) 177-188.

[29]Zhu Q.Y., Xu X.H., Yu J.H., Optimal simplified thermal models of active pipe-embedded building envelope based on frequency-domain finite-difference method using genetic algorithm. ID: 1093, Clima 2013 (11th REHVA World Congress \& 8th International Conference IAQVEC), Prague, Czech Republic, June 16-19, 2013b.

[30]Zhu Q.Y., Xu X.H., Wang J.B., Xiao F., Development of dynamic simplified thermal models of active pipe-embedded building envelopes using genetic algorithm, Int. J. Therm. Sci. 76 (2014) 258-272.

[31]Zhu Q.Y., Xu X.H., Gao J.J., et al. A semi-dynamic model of active pipe-embedded building envelope for thermal performance evaluation. Int. J. Therm. Sci. 88 (2015) 170-179.

[32] Mathew B., Hegab H., Application of effectiveness-NTU relationship to parallel flow microchannel heat exchangers subjected to external heat transfer, International Journal of Thermal Sciences, 49 (1) (2010) 76-85.

[33]ANSI/ASHRAE Standard 138-2009, Method of Testing for Rating Ceiling Panels for Sensible Heating and Cooling. 